\title{
MANCHESTER
}

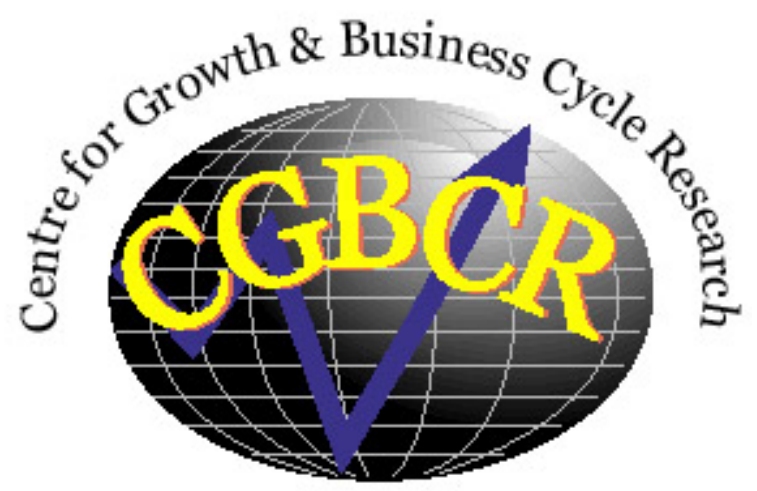

Discussion Paper Series

\section{Entrepreneurs, Legal Institutions and Firm Dynamics}

By

\section{Neus Herranz, Stefan Krasa, Anne P. Villamil}

Centre for Growth and Business Cycle Research, Economic Studies, University of Manchester, Manchester, M13 9PL, UK

October 2009

Number 128

Download paper from:

http://www.socialsciences.manchester.ac.uk/cgbcr/discussionpape rs/index.html 


\title{
Entrepreneurs, Legal Institutions and Firm Dynamics
}

\author{
Neus Herranz* \\ Stefan $\mathrm{Krasa}^{\dagger}$ \\ Anne P. Villamil ${ }^{\ddagger}$
}

October 21, 2009

\begin{abstract}
This paper assesses quantitatively the impact of legal institutions on entrepreneurial firm dynamics. Owners choose firm size, financial structure and default to manage risk. We find: (i) Less risk averse entrepreneurs run bigger firms and it is optimal for them to incorporate, while more risk averse entrepreneurs run smaller firms and generally are better off remaining unincorporated. (ii) More risk-averse owners tend to default more often than the less risk averse, though they carry less debt. (iii) The model estimates a credit constraint, which binds for many but not all entrepreneurs and matches bank lending criteria. The model also finds modest differences in owner risk aversion, consistent with micro studies.
\end{abstract}

JEL Classification Numbers: D92, E01, G33, G38, L25, L26

Keywords: Entrepreneur; Legal Environment; Incorporated; Unincorporated; Endogenous Default; Credit Constraints; Financial Structure; Commitment; Risk Aversion; Heterogeneity

\footnotetext{
${ }^{*}$ Herranz: University of Illinois, Department of Economics, 1407 W. Gregory Street, Urbana, IL 61801 USA; mherranz@illinois.edu

${ }^{\dagger}$ Krasa: University of Illinois, Department of Economics, 1407 W. Gregory Street, Urbana, IL 61801 USA; skrasa@illinois.edu

†Villamil: University of Manchester, Centre for Growth and Business Cycle Research, Oxford Road, Manchester M13 9PL, UK \& University of Illinois, Department of Economics, 1407 W. Gregory Street, Urbana, IL 61801 USA; avillami@illinois.edu

We thank Marco Cagetti, George Deltas, Tim Kehoe, Makoto Nakajima, Stephen Parente, Vincenzo Quadrini and especially discussants Cristina De Nardi and Jamsheed Shorish. We also thank seminar participants at Cambridge, Oxford, University of London, the Conference on Bankruptcy at the IHS in Vienna, Conference on GE at Warwick University, the SAET Conference, and the Milton Friedman Institute-Chicago FED Conference on Finance and Development. We gratefully acknowledge financial support from National Science Foundation grant SES-031839, NCSA computation grant SES050001, the Academy for Entrepreneurial Leadership at the University of Illinois and Kauffman Foundation grant 20061258. Any opinions, findings, and conclusions or recommendations expressed in this paper are those of the authors and do not necessarily reflect the views of the National Science Foundation or any other organization.
} 


\section{Introduction}

Entrepreneurs' decisions about firm legal organization, size, capital structure and default are crucial determinants of firm dynamics. The importance of the link between entrepreneurship and the legal environment is well explained by a quote from a successful entrepreneur, Pat Sullivan, to his wife when they discussed whether or not to start a new business: "In Texas they can't take your house, they can't take your last car and they can't take your kids." After realizing that laws were in place that would limit their personal loss, they decided to start a firm. ${ }^{1}$ The goal of this paper is to assess theoretically and quantitatively the impact of the legal environment on firm dynamics.

Historically, the fundamental role of corporate law was to limit personal liability for business debts; Hovenkamp (1991), pp. 49-55. Supporters of the U.S. Bankruptcy Act of 1800 argued that "unforeseen accidents" were ruining respectable merchants and there was substantial social value in returning these merchants to active business; Mann (2003), note 11, pp. 57, 73. Yet roughly half of all U.S. entrepreneurs are unincorporated, exposing owners to substantial personal risk. This is puzzling because the cost of incorporation is low (government filing fees range from \$25 to \$200) and Herranz, Krasa, and Villamil (2009) show that the puzzle remains when the tax implications of alternative legal forms are accounted for. We construct a model of firm dynamics that explains why both types of firms, incorporated and unincorporated, are optimal and may co-exist.

Bankruptcy insures incorporated owners against poor firm returns, but permits upside gain (though the effect of default on loan interest rates must be accounted for). The contribution of our paper is to show how the legal system affects firm dynamics: entrepreneurs are more willing to bear risk and hence operate larger firms, defaulting only in very bad states, which leads to higher output. ${ }^{2}$ More risk-averse agents may not run firms, but if they do their firms will tend to be small with lower future value. We find that it may be optimal for such owners to leave some personal assets at risk in bankruptcy by remaining unincorporated because this allows them to credibly commit to refrain from "excessive" default. Attitudes toward risk are crucial (e.g., the same bankruptcy rule will have different implications for owners with different degrees of risk aversion), thus we allow for heterogeneity and use the model to derive a distribution of owner risk aversion. In addition to default and firm size decisions, we show that entrepreneurs also manage firm risk by varying the firm's financial structure and the amount of personal net-worth invested.

\footnotetext{
${ }^{1}$ In 1986 Pat Sullivan founded Contact Software International (CSI), a software firm that developed a program to help salespeople manage client records. In 1993 CSI was bought by Symantec Corporation for $\$ 45$ million, and Sullivan was named Entrepreneur of the Year by Inc. magazine. Sullivan often tells this story in business seminars.

${ }^{2}$ The option value of maintaining the firm to realize future value limits default. Owners will "bail out" a firm today with personal funds if they expect sufficient future returns - this is a firm's option value.
} 
We characterize firm dynamics along these dimensions as well.

We construct a model with a risk neutral representative lender and many long-lived agents who may differ in their willingness to bear risk. Each period, agents choose consumption and whether to run a firm with idiosyncratic return risk. If they run a firm, they choose its size, capital structure (mix of personal funds and outside loans), and whether to default ex-post. ${ }^{3}$ Risk cannot be diversified because owners run a single firm, not a portfolio of firms, and firms may be credit constrained. Default occurs in equilibrium, with the lender recovering only a fraction of the loan and the firm unable to obtain credit for several periods. Firms weigh the effect of default today against access to future credit, given bankruptcy rules. Accounting for heterogeneous risk aversion and uncertain firm returns requires us to derive cumulative probability distribution functions linked to firm decisions. We compare model predictions to distributions constructed from data. The discipline imposed by this check for consistency between model predictions and data is the analog of matching moments in quantitative macroeconomic models, see Prescott (2006).

Our principal data source is the Survey of Small Business Finances (SSBF), which shows that most entrepreneurs are owner-managers (in large firms ownership and management are usually separate). In entrepreneurial firms business and personal assets are co-mingled, hence the detailed information in the SSBF on firms and owners is crucial, see Herranz, Krasa, and Villamil (2009). Small firms are a vital part of the macro economy, producing more than 50 percent of non-farm private U.S. GDP, employing half of all private sector employees and paying 45 percent of total private payroll. These firms are a source of "good jobs," generating 60 to 80 percent of net new jobs annually over the last decade, employing 41 percent of high tech workers (scientists, engineers and computer workers) and producing almost 14 times more patents per employee than larger patenting firms. Among all U.S. employer firms, 89 percent have less than 20 employees. ${ }^{4}$ Thus, it is important to understand these firms.

The paper has three main results: First, modest differences in willingness to bear risk interact with firm legal rules and credit constraints to generate significant effects on owners' payoffs. This induces less risk-averse entrepreneurs to run larger firms with higher future value, which limits their incentive to default. Hence, less risk averse owners incorporate to protect personal assets. In contrast, if more risk-averse entrepreneurs run firms they are small with low future value. Such

\footnotetext{
${ }^{3}$ Models with representative agents are aggregated by multiplying the optimal decision rules from the individual's problem by the number of (identical) agents. This is not possible in our setting because differences in willingness to bear risk (i.e., heterogeneous risk aversion parameters) are central to the debate on entrepreneurship. We construct distributions to account for heterogeneity.

${ }^{4}$ See http://www.sba.gov/advo/stats/sbfaq.pdf. In the 1993 and 1998 SSBF, the median number of employees is 7 and median assets are $\$ 270,000$.
} 
owners may optimally leave some personal assets at risk in bankruptcy by remaining unincorporated because this credibly limits default ex-post. Second, we characterize firm dynamics with respect to size, financial structure and default, and show how these endogenous choices are used to manage firm risk. Surprisingly, we find that more risk-averse owners tend to default more often than the less risk averse, but they carry less debt. ${ }^{5}$ Third, we use the model to measure a credit constraint parameter and the distribution of risk aversion. We find that most but not all entrepreneurs are credit constrained and that differences in owners' willingness to bear risk are modest. The credit constraint is consistent with bank lending criteria and the preference results are consistent with micro studies. Overall, our finding that that changes in legal rules and credit constraints can have vastly different impacts on owners' payoffs when they have only small differences in risk aversion, shows that agent heterogeneity and the legal environment are important for policy analysis.

Our analysis requires technical innovation and high performance computing. The ex-post default decision introduces a non-convexity (described below), heterogeneity requires distributions, and the return distribution cannot be captured by the first two moments or a few states. We prove that when an agent's value function is scalable in net worth, the complexity of the problem is reduced. Nevertheless, the problem is computationally intensive because non-convex optimization requires care to find an appropriate start value. Also, constructing distributions for firm size, capital structure and personal net worth invested in the firm requires the fixed point problem to be computed for a sufficiently large number of risk-aversion values to account for agent heterogeneity. Although calibration exercises can typically use small discrete approximations of uncertainty and match moments, we cannot approximate the return distribution by a few states without introducing large errors because the non-normal shape of the distribution matters, see section 7.5. Thus, given continuation values, when computing an agent's utility maximization problem we must use numerical integration in every step of the optimization.

There is a large literature on entrepreneurship. ${ }^{6}$ We focus on how owners use firm size, capital structure and default to manage non-diversifiable risk and the implications for firm dynamics. Our result that firms of less risk-averse owners with a default option tend to be large and have high future value, which credibly limits their incentive to default, is related to Vereshchagina and Hopenhayn (2008)'s model of occupational choice with homogeneous preferences, where risk reduces utility and discourages entrepreneurship. The option to default limits losses, but gains

\footnotetext{
${ }^{5}$ As in Chatterjee, Corbae, Nakajima, and Rios-Rull (2007), default occurs in equilibrium in our model.

${ }^{6}$ See Quadrini (2009) for an excellent survey of three branches of entrepreneurship: (i) factors that affect the decision to become an entrepreneur, (ii) aggregate and distributional implications of entrepreneurship for savings and investment, and (iii) how entrepreneurship affects economic development and growth. See Kihlstrom and Laffont (1979) for an early analysis of differences in risk aversion that formalizes ideas in Knight (1921) in a static model.
} 
are unbounded if the firm is successful. This introduces a kink in the objective function that encourages risk-taking. In Vereshchagina and Hopenhayn (2008) risky projects convexify the kink by providing lotteries over future wealth. We also have a kink in the objective, but cannot use lotteries to convexify it due to a commitment problem - firm size and capital structure decisions are made ex ante but the default decision is made ex-post, and there is no way to enforce expost a firm's ex ante promise to refrain from default. Chen, Miao, and Wang (2009) also study the link between non-diversifiable risk and firm dynamics, but in an asset valuation model with CARA preferences and fixed firm size. An important contribution of their paper is to show how this standard corporate finance approach breaks down when idiosyncratic risk cannot be diversified away. Finally, Abbring and Campbell (2005) formulate and estimate a model of firm dynamics and find that a large component of firm value is due to the option to exit. They focus on differences in firm size due to heterogeneity across entrepreneurs' skills rather than differences in risk aversion.

Our paper also complements recent analyses of the quantitative effects of bankruptcy rules in dynamic models with limited commitment and incomplete markets begun in Athreya (2002). Chatterjee, Corbae, Nakajima, and Rios-Rull (2007) and Livshits, MacGee, and Tertilt (2007) show that U.S. consumer bankruptcy provides partial insurance against bad luck due to health, job, divorce or family shocks, but it drives up interest rates, which impedes intertemporal smoothing. In the latter paper the insurance effect slightly dominates the interest rate effect, while the former finds the reverse. Meh and Terajima (2008) extend the model to study the effect of consumer bankruptcy on unincorporated entrepreneurs and find larger benefits from eliminating the personal bankruptcy exemption, but losses from eliminating consumer bankruptcy entirely. In contrast, our baseline model focuses on bankruptcy by incorporated firms with heterogeneity in owner willingness to bear risk. Bankruptcy provides insurance against poor firm returns, but default is tempered by potentially high future gains from maintaining the firm, due to kurtosis in returns. The insurance effect is much more important than the interest rate effect, especially for owners most willing to bear risk. Also, as mentioned earlier, less risk-averse owners incorporate while more risk-averse owners may not because the seizure of personal assets in bankruptcy mitigates a commitment problem.

The paper proceeds as follows. Section 2 contains the model. Section 3 uses theory to derive a computable problem and constructs cumulative probability distributions predicted by the model for net-worth, capital structure, and firm size. The model is mapped into U.S. data in Section 4. Section 5 shows that the model is quantitatively plausible along a number of dimensions, including firm size, capital structure and default rates. Section 6 examines firm legal status (incorporation). Section 7 reports robustness and section 8 concludes. 


\section{Model with Incorporated Firms}

The economy has $t=0,1, \ldots$ time periods, with a risk-neutral competitive lender and many infinitely lived agents. We assume the lender has an elastic supply of funds and makes one-period loans. ${ }^{7}$ Agents have a common discount rate $\beta$ and preferences that are heterogeneous with respect to risk aversion parameter $\rho \sim N\left(\mu, \sigma^{2}\right)$. Given $\rho$, each agent's CRRA utility function over consumption is given by

$$
u(c)=\frac{c^{1-\rho}}{1-\rho} .
$$

At $t=0$, agents have endowment $w_{0}$ and access to an ex-ante identical constant returns to scale technology. If operated, the technology produces output $x$ per unit of assets invested $A$. The firm's return is given by random variable $X$ with cumulative distribution function $F(x)$ and probability density function $f(x)$, which is strictly positive on support $[\underline{x}, \bar{x}]$, with $\underline{x} \leq 0, \bar{x}>0$, and iid across time periods. A negative realization means that firm losses in a year exceed its current assets; the owner must either use personal funds to stay solvent or default. In all periods $t \geq 1$, agents' networth $w_{t}$ is derived from the return on investment and is known at the beginning of the period. We assume that all agents also have access to an alternative investment opportunity with return $r$.

Entrepreneurs are agents that choose to operate a firm, which means $A>0,{ }^{8}$ and they raise firm assets at time $t$ in two ways:

Equity: Use personal net-worth $w_{t}$ to self-finance at real opportunity cost $r$.

Debt: Take a loan, secured by business assets, at interest rate $r_{L}=\bar{v} /(1-\epsilon)$, where $\bar{v} A$ is the total loan amount that must be repaid in the next period and $(1-\epsilon)$ is the fraction of debt finance. The model has three interest rates:

$r_{L}$ : business loan interest rate (determined endogenously for each entrepreneur by the model);

$r_{f}$ : exogenously given risk-free rate; and

$r$ : exogenously given entrepreneur opportunity cost of providing equity to the firm.

Net-worth $w$ consists largely of illiquid assets, such as home equity or retirement savings. The entrepreneur's opportunity cost of using these personal funds to provide equity to the firm, $r$, is thus higher than risk-free rate $r_{f}$, the lender's opportunity cost of funds, meaning that lenders (banks) have better access to funds than entrepreneurs. Since entrepreneurs default with positive

\footnotetext{
${ }^{7}$ We consider a composite lender that supplies all liabilities (bank loans, trade credit and other liabilities) and can infer borrower risk aversion. The average maturity on loans to small firms is less than one year in the Federal Reserve's Survey of Terms of Business Lending (these firms lack audited financial statements, payment or profit histories, or verifiable contracts with workers, suppliers or customers).

${ }^{8}$ If agents do not wish to run a firm, they set $A=0$ and consume $w_{t}$.
} 
probability in equilibrium, the lender's loan rate $r_{L}$ generally exceeds $r$. Given a level of business assets $A$ in a period, the entrepreneur determines the optimal financial structure by choosing the fraction of self-finance $\epsilon$. Thus, total equity is $\epsilon A$ and total debt is $(1-\epsilon) A$ at the beginning of the period, while at the end of the period the firm has assets $x A$ and liabilities $\bar{v} A$.

The firm faces a borrowing constraint, $(1-\epsilon) A \leq b w$, which limits business loans to fraction $b$ of entrepreneur net-worth. If our model were static, this constraint would be identical to Evans and Jovanovic (1989). Our constraint depends on agent net-worth $w$, however, which evolves over time and includes both firm and personal assets. ${ }^{9}$ Of course firm assets can be seized in bankruptcy, but the constraint indicates that the lender also takes account of the fact that the entrepreneur will use personal assets to "bail out the firm" (when this is optimal). Because the project's expected return exceeds the lender's opportunity cost of funds plus expected default costs, the risk neutral lender would like projects to be highly levered and run at a large scale. This constraint imposes lending limits on entrepreneurs of each risk type. We will use the model to estimate $b$.

Ex-post, the entrepreneur chooses whether to repay loan $A \bar{v}$ or default. ${ }^{10}$ When default occurs, bankruptcy follows immediately and is described by two parameters, $\delta$ and $T$. The court determines the total value of firm assets and transfers $1-\delta$ to the lender, where $\delta$ is a deadweight bankruptcy loss (e.g., firm assets are sold at a loss). As the firm is incorporated, the entrepreneur is protected by limited liability (only firm assets can be seized), but has the option to pay firm debt with personal funds if this is optimal. If bankruptcy occurs, the entrepreneur does not have access to the firm's returns for $T$ periods, which has two interpretations. First, corresponding to Chapter 7 in the U.S. Bankruptcy Code, the firm may be liquidated. Because bankruptcy remains on a credit record for a period of time, creditors and customers would be unwilling to do business with the entrepreneur during this period. Second, corresponding to Chapter 11, the firm may continue to operate, but is owned by the debt-holders who make investments and receive payments, or shut it down. After $T$ periods the credit record is clean, and the entrepreneur can either restart a new firm or regain control of the original firm, in Chapter 7 or 11 respectively.

The timing of events for incorporated firms is as follows:

1. Beginning of period $t$ (ex-ante) entrepreneur net-worth is $w$. There are two cases:

\footnotetext{
${ }^{9}$ The risky technology and $w_{0}$ are ex-ante identical, but net-worth (and consumption) evolve stochastically over time due to differences in risk aversion and return realizations. As $b \rightarrow \infty$, borrowing is unconstrained.

${ }^{10} \mathrm{~A}$ firm may default if it is unable to repay $A \bar{v}$ (firm plus personal assets are less than $A$ ) or unwilling to repay. Owners can "bail out the firm" with personal assets to forestall bankruptcy, but cannot be forced to do so. In our model personal credit histories affect business loans, causing a credit interruption. Mester (1997) p. 7 finds that in small business loan scoring models, "the owner's credit history was more predictive than net worth or profitability of the business" and "owners' and businesses' finances are often commingled."
} 
(a) The entrepreneur did not declare bankruptcy in any of the previous $T$ periods: Choose consumption $c$, firm assets $A$, self-finance $\epsilon$ (debt is $1-\epsilon$ ), and amount $\bar{v}$ to repay per unit $A$, subject to the lender receiving at least ex-ante expected payoff $(1-\epsilon)\left(1+r_{f}\right)$.

(b) The entrepreneur declared bankruptcy $k$ periods ago. The owner cannot operate the firm for the next $T-k$ periods. Hence, only current consumption is chosen.

2. At the end of period $t$ (ex-post) the firm's return on assets, $x$, is realized. Total end-of-period firm assets are $A x$. The entrepreneur must decide whether or not to default. If

(a) Default: Only firm assets are seized; the entrepreneur is left with personal net-worth $(1+r)(w-\epsilon A-c)$, personal assets invested at outside interest rate $r$.

(b) No Default: Entrepreneur net-worth is $A(x-\bar{v})+(1+r)(w-\epsilon A-c)$, which includes both net-equity in the firm and the return on personal assets.

\section{An Individual Agent's Problem}

Consider the optimization problem of an agent, with a given coefficient of risk aversion $\rho$. The goal is to determine the structure of the value function. We state the problem recursively, with beginning of period entrepreneur net-worth $w$. If bankruptcy occurred in the previous $T$ periods, then the state is given by $(B, k, w)$ where $k$ is the number of periods since default. Otherwise, the state is given by $(S, w)$. Denote the value functions by $V_{B, k}(w)$ and $V_{S}(w)$, respectively. After $T$ periods the firm can restart, thus $V_{B, T}(w)=V_{S}(w)$. Let $\mathfrak{B}$ denote the set of asset return realizations $x$ for which bankruptcy occurs, with complement $\mathfrak{B}^{c}$.

If the firm did not default in the previous $T$ periods, the agent solves:

Problem $1 V_{S}(w)=\max _{c, A, \epsilon, \bar{v}} u(c)+\beta\left[\int_{\mathfrak{B}} V_{B, 1}((1+r)(w-\epsilon A-c)) d F(x)\right.$

$$
\left.+\int_{\mathfrak{B}^{c}} V_{S}(A(x-\bar{v})+(1+r)(w-\epsilon A-c)) d F(x)\right]
$$

Subject to:

$$
\begin{gathered}
\int_{\mathfrak{B}_{\mathbb{R}_{-}}} x d F(x)+\int_{\mathfrak{B}_{\mathbb{R}_{+}}}(1-\delta) x d F(x)+\int_{\mathfrak{B}^{c}} \bar{v} d F(x) \geq(1-\epsilon)\left(1+r_{f}\right) \\
x \in \mathfrak{B} \text { if and only if } V_{B, 1}((1+r)(w-\epsilon A-c))>V_{S}(A(x-\bar{v})+(1+r)(w-\epsilon A-c)) \\
(1-\epsilon) A \leq b w
\end{gathered}
$$




$$
c \geq 0, A \geq 0,0 \leq \epsilon \leq 1
$$

The objective is an agent's utility of current consumption plus the discounted continuation value of end of period net-worth. Constraint (1) ensures that the lender is willing to supply funds. The right-hand-side indicates that the $1-\epsilon$ fraction of funds the lender invests in the firm earn at least reservation return $1+r_{f}$. The left-hand side is the lender's expected return from the loan: the first term accounts for the fact that the lender may absorb some losses when the firm's return is negative, ${ }^{11}$ the second term is the net amount recovered from firm assets in bankruptcy states with positive net returns (deadweight default loss $\delta$ arises only if $x$ is positive and the firm has not lost more than the value of its assets in the period), the third term is the net amount recovered from personal assets and the fourth term is the fixed debt repayment in solvency states. Constraint (2) specifies ex-post optimality of the default decision: An entrepreneur will default if and only if the expected continuation payoff after default exceeds that from solvency. ${ }^{12}$ As discussed previously, (3) is the borrowing constraint. Finally, (4) is standard. ${ }^{13}$

Now consider the problem of a firm that defaulted $k \leq T$ periods ago. After $T$ periods the firm can operate again, thus $V_{B, T}(\cdot)=V_{S}(\cdot)$. Let $w^{\prime}$ denote net-worth next period.

Problem $2 V_{B, k}(w)=\max _{c, w^{\prime}} u(c)+\beta V_{B, k+1}\left(w^{\prime}\right)$

Subject to:

$$
\begin{gathered}
c(1+r)+w^{\prime} \leq w(1+r) \\
c, w^{\prime} \geq 0
\end{gathered}
$$

The objective of problem 2 is expected ex-ante utility. If default occurred, the agent cannot operate the firm for $T$ periods and chooses only consumption and saving, consistent with budget constraint (5) and non-negativity constraint (6).

We now use the fact that CRRA utility is scalable in wealth to determine the structure of the

\footnotetext{
${ }^{11}$ This can occur if the loan has an overdraft provision or the firm has trade credit. In the data, this corresponds to the case where the firm has negative equity and defaults.

${ }^{12}$ Bailing out the firm with personal funds means that the entrepreneur continues to operate the firm even if $x<\bar{v}$. In a one period model (instead of the dynamic model) both $V_{B, 1}$ and $V_{S}$ would be the identity mapping, and (2) would reduce to $x \in \mathfrak{B}$ if and only if $(1+r)(w-\epsilon A-c)>A(x-\bar{v})+(1+r)(w-\epsilon A-c)$, which implies $x \in \mathfrak{B}$ if and only if $x<\bar{v}$ (bankruptcy only if the return is less than debt plus interest).

${ }^{13}$ Ex ante $0<\epsilon<1$, but ex-post negative equity may occur. This distinction arises because the non-negativity constraint on equity only applies ex ante. Ex-post, if the project realization is low, assets are low and end-of-period equity will be negative due to the accounting identity: assets = debt + equity.
} 
value function. Proposition 1 determines the shape of the value function, which will allow us to restate Problem 1 as a one-dimensional fixed point problem. ${ }^{14}$ The proof is in Appendix B.

Proposition 1 Suppose that the entrepreneur has constant relative risk aversion. Let $v_{S}=V_{S}(1)$ and $v_{B, k}=V_{B, k}(1)$. Then $V_{S}(w)=w^{1-\rho} v_{S}$ and $V_{B, k}(w)=w^{1-\rho} v_{B, k}$.

Applying Proposition 1 to Problem 2 it is straightforward to compute $v_{B, k}$ as a function of $v_{S}$. Further, Lemma 1 and Lemma 2 in Appendix B prove that the investor's constraint binds and bankruptcy set $\mathfrak{B}$ is a lower interval, with cutoff $x^{*}$. Thus, the optimization problem can be rewritten as follows, where all endogenous variables are expressed as a fraction of net-worth $w$ :

Problem $3 v_{S}=\max _{c, A, \epsilon, \bar{v}} u(c)+\beta v_{B} \int_{\underline{x}}^{x^{*}}[(1+r)(1-\epsilon A-c)]^{1-\rho} d F(x)$

$$
\left.+\beta v_{S} \int_{x^{*}}^{\bar{x}}[A(x-\bar{v})+(1+r)(1-\epsilon A-c)]^{1-\rho} d F(x)\right]
$$

Subject to:

$$
\begin{gathered}
\int_{\underline{x}}^{x^{*}} \min \{(1-\delta) x, x\} d F(x)+\int_{x^{*}}^{\bar{x}} \bar{v} d F(x)=(1-\epsilon)\left(1+r_{f}\right) \\
x^{*}=\max \left\{\bar{v}-\left[1-\left(\frac{v_{B}}{v_{S}}\right)^{\frac{1}{1-\rho}}\right] \frac{(1+r)(1-\epsilon A-c)}{A}, \underline{x}\right\} \\
c+\epsilon A \leq 1 \\
(1-\epsilon) A \leq b \\
c \geq 0, A \geq 0,0 \leq \epsilon \leq 1 .
\end{gathered}
$$

The objective is to maximize the utility of current consumption and the discounted value of end of period net-worth in firm bankruptcy and solvency states. Constraint (7) corresponds to lender individual rationality constraint (1), and binds by Lemma 1 in Appendix B. Constraint (8) is the optimal default cutoff and follows from (2) by Lemma 2. (9) ensures feasibility and (10) is the borrowing constraint. (11) is obvious.

\footnotetext{
${ }^{14} \mathrm{We}$ need only $v_{B, 1}$, the continuation utility given that default was just announced, and $v_{S}$. To simplify notation, write $v_{B}$ for $v_{B, 1}$.
} 
Problem 3 is non-convex because the timing of decisions leads to a commitment problem: $c$, $A, \epsilon, \bar{v}$ are chosen ex-ante, but the bankruptcy decision is made ex-post and the firm cannot commit to refrain from bankruptcy. This implies that default set cutoff $x^{*}$ is determined by (8). Lotteries cannot be used to convexify the problem because independent randomization over $A, \epsilon, c, \bar{v}$ and $x^{*}$ is not possible. See Krasa and Villamil (2000), Krasa and Villamil (2003) for an analysis of randomization and commitment.

\subsection{Existence and Uniqueness}

Proposition 2 There exist $\underline{\rho}<1$ and $\bar{r}>\frac{1}{\beta}-1$ such that Problem 3 has a solution for all $\rho \geq \underline{\rho}$ and for all $r \leq \bar{r}$.

Let $\Gamma\left(v_{S}\right)$ be the expected utility given continuation value $v_{S}$. In general $\Gamma^{\prime}\left(v_{S}\right)>1$ for all $v_{S}$ close to 0 . Thus, $\Gamma$ is not a contraction mapping because net-worth is unbounded. In the proof of Proposition 2 in Appendix B, we show that $\Gamma(0) \leq 0$ and that there exists $v_{S}$ such that $\Gamma\left(v_{S}\right) \geq 0$ for risk aversion $\rho>1$. As a consequence of the intermediate value theorem, continuity of $\Gamma$ implies that $\Gamma$ has a fixed point. By continuity, the result extends for some $\rho<1$.

If there is more than one solution to the recursive problem, then the solution with the maximal $v_{S}$ corresponds to the solution of the infinite horizon problem where agents select sequences for consumption, assets, debt-equity and default.

\subsection{Heterogeneous Entrepreneurs \& Model Predictions}

Agents are heterogeneous with respect to risk aversion. This requires matching model predictions and data in terms of distributions (see Krusell and Smith (1998)). We now specify the distributions predicted by the model for end-of-period firm assets, personal net-worth invested in the firm, and the ratio of equity over assets (firm capital structure). Given firm return pdf $f(x)$ and risk aversion pdf $g_{\mu, \sigma}(\rho)$, the cdfs predicted by the model are: ${ }^{15}$

Cdf of Net-Worth: After realization $x$, firm assets are $A(\rho) x$ and debt is $A(\rho) \bar{v}$. Equity in the firm is $A(\rho)(x-\bar{v}(\rho))$, which is positive if $x \geq \bar{v}(\rho)$. Owner personal net-worth outside the firm is $(1+r)(1-c(\rho)-\epsilon(\rho) A(\rho))$. The fraction of total net-worth invested is

$$
\mathfrak{w}=\frac{A(\rho)(x-\bar{v}(\rho))}{A(\rho)(x-\bar{v}(\rho))+(1+r)(1-c(\rho)-\epsilon(\rho) A(\rho))} .
$$

\footnotetext{
${ }^{15}$ We will construct $f(x)$ and $g_{\mu, \sigma}(\rho)$ in the quantitative analysis.
} 
It follows immediately that $\mathfrak{w}$ is strictly increasing in $x$. We can solve this equation for $x=x(\mathfrak{w}, \rho)$. The fraction of net-worth invested is less than or equal to $\mathfrak{w}$ for all $x \leq x(\mathfrak{w}, \rho)$. For firms with positive equity, the cdf of net worth is therefore given by ${ }^{16}$

$$
W_{\mu, \sigma}^{m}(\mathfrak{w})=\frac{\int_{-\infty}^{\rho} \int_{\bar{v}(\rho)}^{x(\mathfrak{w}, \underline{\rho})} f(x) g_{\mu, \sigma}(\rho) d x d \rho+\int_{\underline{\rho}}^{\infty} \int_{\bar{v}(\rho)}^{x(\mathfrak{w}, \rho)} f(x) g_{\mu, \sigma}(\rho) d x d \rho}{\int_{\bar{v}(\rho)}^{\infty} f(x) d x} .
$$

Cdf of Equity/Assets: The fraction of equity is given by

$$
\mathrm{e}=\frac{A(\rho)(x-\bar{v}(\rho))}{A(\rho) x} .
$$

Solve this equation for $x=x(\mathfrak{e}, \rho)$. For firms with positive equity, the cdf of equity/assets is then

$$
E_{\mu, \sigma}^{m}(\mathfrak{e})=\frac{\int_{-\infty}^{\underline{\rho}} \int_{\bar{v}(\rho)}^{x(\mathfrak{e}, \underline{\rho})} f(x) g_{\mu, \sigma}(\rho) d x d \rho+\int_{\underline{\rho}}^{\infty} \int_{\bar{v}(\rho)}^{x(\mathrm{e}, \rho)} f(x) g_{\mu, \sigma}(\rho) d x d \rho}{\int_{\bar{v}(\rho)}^{\infty} f(x) d x} .
$$

Cdf of End of Period Assets: The current realization of end of period assets as a fraction of net-worth outside the firm is

$$
\mathfrak{a}=\frac{A(\rho) x}{(1+r)(1-c(\rho)-\epsilon(\rho) A(\rho))}
$$

Solve this equation for $x=x(\mathfrak{a}, \rho)$ to get the cdf of end of period assets

$$
A_{\mu, \sigma}^{m}(\mathfrak{a})=\int_{-\infty}^{\underline{\rho}} \int_{\underline{x}}^{x(\mathfrak{a}, \underline{\rho})} f(x) g_{\mu, \sigma}(\rho) d x d \rho+\int_{\underline{\rho}}^{\infty} \int_{\underline{x}}^{x(\mathfrak{a}, \rho)} f(x) g_{\mu, \sigma}(\rho) d x d \rho .
$$

\section{Mapping the Model to U.S. Data}

Table 1: Exogenous Parameters

\begin{tabular}{|c|c|c|c|}
\hline Parameter & Interpretation & Value & Comment/ Observations \\
\hline$r_{f}$ & lender opportunity cost & $1.2 \%$ & real rate, 6 mo T-Bill, 1992-2006 \\
$r$ & entrepreneur opportunity cost & $4.5 \%$ & real rate, 30 year mortgage, 1992-2006 \\
$\beta$ & discount factor & 0.97 & determined from $r$ and $r_{f}$ \\
$T$ & default exclusion period & 11 & U.S. credit record \\
$\delta$ & default deadweight loss & 0.10 & Boyd-Smith (1994) \\
\hline
\end{tabular}

\footnotetext{
${ }^{16}$ The denominator is the probability that the entrepreneur has positive equity, where $\rho$ is the lowest parameter for which a model solution exists. For all $\rho<\underline{\rho}$ we assign the model solution as explained in section 5.
} 
We use U.S. data to assign values to five model parameters and to construct the distribution of firm returns. We jointly calibrate three remaining parameters. In table 1 , we identify $r_{f}$, the lender's opportunity cost of short-term funds, with the average real return on 6 month Treasury bills between 1992 and 2006. ${ }^{17}$ The interest rate charged by the lender will be strictly higher than $r_{f}$ because of bankruptcy costs. We identify the owner's opportunity cost of funds $r$ with the real rate on 30 year mortgages over the period; the cost of using home equity to finance a business loan will also be strictly higher. $\beta=0.97$ is approximated by $1 /\left(1+0.5 r_{f}+0.5 r\right)$, with $r$ and $r_{f}$ weighed equally (firm risk cannot be diversified since a portfolio of small firms does not exist). The bankruptcy parameters are $T=11$, because in the U.S. after 10 years past default is removed from a credit record, and $\delta=0.1$, the bankruptcy deadweight loss in Boyd and Smith (1994) and the midpoint of costs of 0-20\% of assets in Bris, Welch, and Zhu (2006).

Herranz, Krasa, and Villamil (2009) use data from the Survey of Small Business Finances (SSBF) on incorporated firms to compute firm return distribution $f(x) .{ }^{18}$ They assume firms have access to a common constant returns to scale "blue print" technology. The return per unit of assets for a particular firm is a sample point from this distribution (see section 10.1). Table 2 shows that $f(x)$ is risky, with rightward skew and a long upper tail. ${ }^{19}$

Table 2: Real Firm Return on Assets for Incorporated Firms: Summary Statistics

\begin{tabular}{|c|c|c|c|c|c|}
\hline Moment: & median & mean & standard dev. & skewness & kurtosis \\
\hline 1993 SSBF & 1.094 & 1.30 & 1.57 & 13.2 & 290 \\
95\% conf. & {$[1.08,1.11]$} & {$[1.22,1.38]$} & {$[0.95,2.13]$} & {$[2.3,17.3]$} & {$[29,488]$} \\
\hline
\end{tabular}

The remaining parameters are jointly calibrated by choosing $b, \mu, \sigma$ to minimize the distance between model predictions and data. We first construct two empirical cumulative density functions

\footnotetext{
${ }^{17}$ We use monthly data for T-Bill rates and deduct for each month the CPI reported by the BLS.

${ }^{18}$ The SSBF was administered by the Board of Governors of the Federal Reserve System and the U.S. Small Busi-

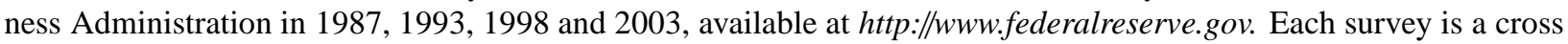
section of about 4000 non-farm, non-financial, non-real estate small businesses that represents about 5 million firms. The surveys contain information on small firms and the primary owner (e.g., owner age, gender, industry, type of business organization), firm income statements and balance sheets, details on the use and source of financial services, and recent firm borrowing experience (including trade credit and capital injections such as equity). We consider only incorporated firms with assets of at least $\$ 50,000$. We impose this lower bound on assets for numerical reasons: we divide profits by assets to get returns and 50,000 is the smallest number that did not generate numerical problems but left almost all of the sample intact.

${ }^{19} 95 \%$ confidence bands are computed for each moment using bootstrap sampling, except the interquartile range is reported for the median. Only the 1993 SSBF has interest payments, required to compute return on assets.
} 
from the SSBF data. The empirical cdf of net-worth invested is, $W^{e}(\mathfrak{w}):^{20}$

$\frac{\text { owners' share } * \text { equity }}{\text { net-worth outside the firm }+ \text { owners' share } * \text { equity }}$.

The empirical cdf of end-of-period assets per unit of net-worth, $A^{e}(\mathfrak{a})$, is:

$$
\frac{\text { owners' share } * \text { asset }}{\text { net-worth outside the firm }} \text {. }
$$

The model-predicted median assets are $\mathfrak{a}_{\mu, \sigma}$ such that $A_{\mu, \sigma}^{m}\left(\mathfrak{a}_{\mu, \sigma}\right)=0.5$.

Parameters $b, \mu, \sigma$ are chosen to minimize the supnorm distance between the cdf implied by the model and the cdf from the SSBF data:

$$
\min _{b, \mu, \sigma \geq 0}\left\|W_{\mu, \sigma}^{m}(\mathfrak{w})-W^{e}(\mathfrak{w})\right\|_{\infty}+\left(0.431-\mathfrak{a}_{\mu, \sigma}\right)^{+}+\left(\mathfrak{a}_{\mu, \sigma}-0.519\right)^{+}
$$

The cdf of net-worth invested implied by the model, $W_{\mu, \sigma}^{m}(\mathfrak{w})$, is given by (13). The supremum norm $\|.\|_{\infty}$ is taken over all non-negative fractions of net-worth. ${ }^{21}$ The second and third terms impose penalties only for asset values outside the $95 \%$ confidence interval for firm assets, which Herranz, Krasa, and Villamil (2009) find is [43.1,51.9]. Since we exclude firms with negative equity when determining $W^{e}$, net-worth invested is between $0 \%$ and $100 \%$, but assets are unbounded. ${ }^{22}$ The lack of a well defined upper bound for assets is a problem because tail behavior would greatly impact model prediction; requiring the median asset level to lie in its $95 \%$ confidence interval solves this problem.

Table 3: Calibrated Parameters

\begin{tabular}{|c|c|c|}
\hline Parameter & Interpretation & Est. Value \\
\hline$b \%$ & borrowing constraint: loan $\leq b w$ & 21.5 \\
$\mu$ & median of distribution of risk aversion & 1.55 \\
$\sigma$ & standard deviation of distribution of risk aversion & 0.83 \\
\hline
\end{tabular}

Table 3 reports the calibrated parameters. The model predicts a maximal ex ante loan size of $21.5 \%$ of entrepreneur net-worth inside and outside the firm. To put this number in perspective,

\footnotetext{
${ }^{20} W^{e}(\mathfrak{w})$ is the number of observations, accounting for sample weights, at which the fraction of net-worth invested is less than or equal to $\mathfrak{w}$.

${ }^{21}$ To compute the supremum norm we evaluate $\left|W_{\mu, \sigma}^{m}(\mathfrak{w})-W^{e}(\mathfrak{w})\right|$ at 1,000 equi-distant points between 0 and 1 , and take the maximum. Appendix $\mathrm{C}$ shows the estimates are not affected by using square distance

$$
\sqrt{\int\left(W_{\mu, \sigma}^{m}(\mathfrak{w})-W^{e}(\mathfrak{w})\right)^{2} d \mathfrak{w}+\left(\left(0.431-\mathfrak{a}_{\mu, \sigma}\right)^{+}\right)^{2}+\left(\left(\mathfrak{a}_{\mu, \sigma}-0.519\right)^{+}\right)^{2}}
$$

${ }^{22}$ For example, $5 \%$ of firms had assets over ownership share that exceeded owner net-worth by $500 \%$.
} 
consider its implications for small business lending. In order to be considered for a commercial loan, three criteria must generally be satisfied: ${ }^{23}$

(i) The loan amount cannot exceed collateral.

(ii) Annualized loan repayment cannot exceed half of business cash flow.

(iii) The debt-equity ratio $(1-\epsilon) / \epsilon$ cannot exceed 3 .

Criterion (i) is straightforward, but difficult to check empirically. Owners can pledge firm assets $A$ as collateral (if they exist) and use personal assets to bail out the firm. However, SSBF data provide only an incomplete picture of firm collateral and it is not possible to distinguish "equilibrium firm bailouts" via personal collateral from standard equity injections in any data base.

Our model is crucial for assessing (ii) and (iii). For (ii), the SSBF does not provide information on annualized loan repayment (cash flow is $A x$ ), but the ex-ante debt-equity ratio is easily identified in the data. However, it depends on entrepreneur risk aversion, which is not observable. We use the risk aversion coefficients implied by the model to compute model debt-equity ratios and check if they are consistent with SSBF data. The model's median risk-aversion estimate of 1.55 implies an ex-ante debt-equity ratio of 2 , which clearly satisfies (iii). The limit of 3 is reached when $\rho=2.3$, which is roughly one standard deviation above the mean $\rho$. Thus, the value of $b$ estimated by the model implies that more than $80 \%$ of firms fall within bank business loan guideline (iii). Of course, this is a guideline and some entrepreneurs may be able to borrow at higher rates. For example, SBA loans allow debt-equity ratios of up to 4 as a matter of public policy, and trade credit is not subject to this guideline. Such factors may explain debt-equity ratios exceeding 3 for the remaining $20 \%$ of entrepreneurs.

The prediction for $\epsilon$ can be checked similarly. If the lender uses the median return, (iii) gives $(1-\epsilon) A \leq(1.094 / 2) A$ and the mean gives $(1-\epsilon) A \leq(1.30 / 2) A$ (see table 2$)$. This yields $\epsilon \geq 0.453$ or $\epsilon \geq 0.35$, respectively, which are tighter than debt-equity ratio constraint (iii). In the model, they are fulfilled for all $\rho \leq 1.01$ or $\rho \leq 1.51$. If $b$ were larger, the predicted $\epsilon$ would be higher with (iii) violated for more firms. Interestingly, a standard consumer loan guideline requires housing payments to not exceed $28 \%$ of gross annual income. Business loans are (normally) riskier than mortgages, roughly implying a lower constraint, which also suggests estimate $b$ is reasonable. Thus, the model's estimate of $b$ is roughly consistent with established lending practices.

The model also estimates the median level of risk aversion of owner of an incorporated firm, finding $\mu=1.55$ with standard deviation $\sigma=0.83$. We use these estimates to construct the

\footnotetext{
${ }^{23}$ See $h t t p: / / w w w . s b a . g o v / l o c a l r e s o u r c e s / d i s t r i c t / f /$ north/JK_CIQUAL.html.
} 
distribution of risk aversion for incorporated firms, $g_{\mu, \sigma}(\rho)$, the final object in the model that must be mapped into data. To put this estimate in perspective, we again compare it with other studies. Mazzocco (2006) uses the Consumer Expenditure Survey to estimate a median coefficient of risk aversion of 1.7 for men. We would expect entrepreneurs to be somewhat less risk averse than the general population, and our estimate for $\rho$ is in line with this. ${ }^{24}$ About $75 \%$ of our agents have a coefficient of risk aversion between 1 and 3 , the range used in real business cycle models. Our result is also broadly consistent with results from laboratory experiments, e.g., Harrison, List, and Towe (2009) find that CRRA describes the data well, modest heterogeneity, and a lower mean.

Appendix A shows that the values of the calibrated parameters do not vary significantly with legal parameters $\delta$ and $T$. The insensitivity to changes in $\delta$ is due to the low equilibrium default rate. Table 12 shows that the best model fit is obtained at a value of $T=13$. Thus, if we calibrated $T$ instead of choosing it to be consistent with U.S. institutions, the numbers for the calibrated parameters and model results do not change significantly.

\section{Matching Model Predictions and Data}

Our model is quantitatively plausible along a number of dimensions. Figure 1 compares the cdfs predicted by the model (computed as explained in section 3.2) with SSBF data. ${ }^{25}$ The first panel shows the model-predicted and empirical cdfs for the fraction of net-worth an owner invests in the firm. Since we fit to this empirical cdf one would expect to see a match, but the match is surprisingly good given there are only three fitting parameters. The data show that owners invest substantial personal net-worth in their firms: the median is $21 \%$ and the mean is $27 \%$. The data also show a surprising lack of diversification: $3 \%$ invest more than $80 \%, 11 \%$ invest more than $60 \%, 25 \%$ invest more than $40 \%$ and $52 \%$ invest more than $20 \%$. The model replicates these facts.

The next panel compares the predicted cdf of firm assets to its empirical counterpart. The match between these cdfs is also good, but the model under predicts a few large firms. This occurs because model solutions do not exist below $\underline{\rho}=0.74$, and we assign point mass of $\mu(\{\rho \leq \bar{\rho}\})$ to $\underline{\rho}$. At $\underline{\rho}$, the ex-ante level of $\epsilon$ and $A$ are 0.720 and 0.766 , respectively. Thus, end of period net-worth outside the firm, $(1-\epsilon A-c)(1+r)$ is about 0.470 . Using median return $\hat{x}=1.094$ from table 2, the ex-post level of assets as a fraction of net-worth for risk aversion level $\underline{\rho}$ is

\footnotetext{
${ }^{24}$ Mazzocco (2006) does not estimate the distribution of risk aversion, so his estimate of the standard deviation of 0.96 is not directly comparable to ours.

${ }^{25}$ Only the 1998 SSBF has owner net worth, personal net-worth plus home equity. The data cdf for net-worth invested is for firms with positive net-worth outside the firm, non-negative equity, and at least $\$ 50,000$ in assets.
} 

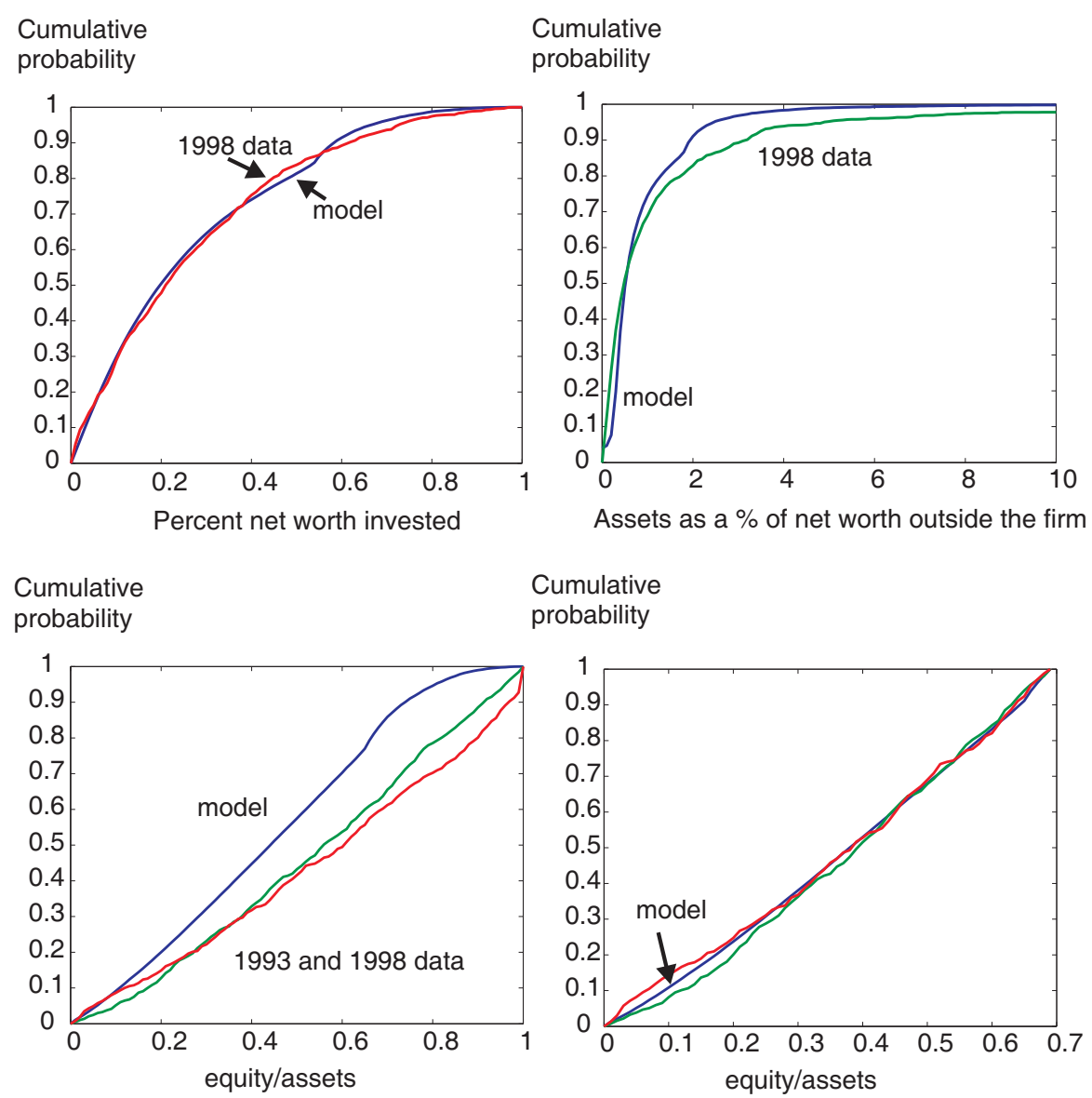

Figure 1: Model Predictions and SSBF Data for incorporated firms: cdfs

$A \hat{x} /(1-\epsilon A-c)(1+r))=1.786$. In the graph, this is the range where the model predicted curve moves away from the data. The model predicted median asset level of $48.1 \%$ in table 4 below is well within the $95 \%$ confidence interval of $[43.1,51.9]$. This also shows that the penalty term in (17) is not relevant in the neighborhood of the optimal parameters.

The bottom panels of figure 1 compare the model prediction for firm capital structure to the empirical cdfs for 1993 and 1998. The left panel shows that the model somewhat over predicts equity/assets. This again occurs because no model solutions exist below $\rho$ and (14) assigns point mass to these values. At $\underline{\rho}=0.74$ the associated value of $\bar{v}$ is 0.335 . At median return level $\hat{x}=1.094$, this gives an ex post value of equity/assets of $(\hat{x}-\bar{v}) / \hat{x}=0.7$, which is where the kink in the left panel occurs. If the cdf of $\epsilon$ is computed conditional on $\epsilon<0.7$, the model does an excellent job of replicating the empirical distribution of equity/assets among firms - see the right panel. By definition total assets are debt plus equity, thus equity/assets is a measure of firm capital structure. The approximately uniform cdf indicates that all capital structures are equally likely and 
Table 4: Model Point Estimates

\begin{tabular}{|c|c|c|c|}
\hline Parameter & Interpretation & Model & Data \\
\hline median $A \%$ & median firm assets (size) & 48.1 & {$[43.1,51.9]$} \\
consumption $\%$ & consumption as a fraction of net worth & 3.6 & $3-5$ \\
default \% & small firm default rate & 4.4 & $3.5-4.5$ \\
neg. equity $\%$ & negative equity in the firm & 10.6 & $15.7,21.0$ \\
\hline
\end{tabular}

this suggests agent heterogeneity, if individual firm capital structure is optimal. ${ }^{26}$

Table 4 shows that the model replicates successfully other targets. Median firm assets match well (as discussed above) and consumption is in the standard range. ${ }^{27}$ The default prediction is slightly higher than the average annual default rate of $3.5 \%$ on small business loans guaranteed by the Small Business Administration in Glennon and Nigro (2005) and close to the default rate on trade credit of $4.5 \%$ in Boissay and Gropp (2007), table 2.4, for small French firms. ${ }^{28}$ Negative equity, accounted for in the model in constraint (1), indicates that non-business assets are used to cover business losses (e.g., personal funds or unpaid bills absorbed by creditors). The model value of $10.6 \%$ is below the SSBF empirical values for all firms of $15.7 \%$ in 1993 and $21.0 \%$ in 1998 . The use of personal funds to "bail out" a firm may seem puzzling since we consider only incorporated firms, which are protected by limited liability in bankruptcy. Why do these entrepreneurs not simply default on their loans? In a dynamic model an entrepreneur will not default, and hence will choose to bailout a poorly performing firm with personal funds, if the firm's expected discounted continuation value is sufficiently high. While the benchmark model's predicted level of negative equity falls short of the values observed in the SSBF, section 7.4 will show the model can better match the data if entrepreneurs are slightly optimistic.

Table 5: Entrepreneur's Ex-Ante Optimal Choice and Risk Aversion

\begin{tabular}{|c|c|c|c|c|c|c|c|c|c|}
\hline $\boldsymbol{\rho}$ & $\mathbf{0 . 9}$ & $\mathbf{1 . 2}$ & $\mathbf{1 . 5}$ & $\mathbf{1 . 8}$ & $\mathbf{2 . 1}$ & $\mathbf{2 . 5}$ & $\mathbf{3 . 0}$ & $\mathbf{3 . 5}$ & $\mathbf{4 . 0}$ \\
\hline$(1-\epsilon) A \%$ & 21.5 & 21.5 & 21.5 & 21.5 & 21.5 & 18.7 & 15.2 & 12.8 & 11.1 \\
$A \%$ & 61.0 & 44.2 & 35.3 & 30.0 & 27.0 & 22.7 & 18.3 & 15.4 & 13.3 \\
$\epsilon \%$ & 64.8 & 51.5 & 39.1 & 28.5 & 20.4 & 17.6 & 17.2 & 16.8 & 16.5 \\
$\bar{v}$ & 0.409 & 0.550 & 0.682 & 0.798 & 0.891 & 0.921 & 0.925 & 0.928 & 0.930 \\
default \% & 3.6 & 3.7 & 4.0 & 4.6 & 5.4 & 5.6 & 5.4 & 5.2 & 5.1 \\
$c \%$ & 2.2 & 4.0 & 4.6 & 4.9 & 5.0 & 5.0 & 5.0 & 4.9 & 4.9 \\
\hline
\end{tabular}

\footnotetext{
${ }^{26} \mathrm{~A}$ uniform distribution for all firms is consistent with a determinate capital structure for each firm.

${ }^{27}$ Point estimates for expected fraction of net-worth spent on consumption and the default probability are $\int_{-\infty}^{\underline{\rho}} c(\underline{\rho}) g_{\mu, \sigma}(\rho) d \rho+\int_{\underline{\rho}}^{\infty} c(\rho) g_{\mu, \sigma}(\rho) d \rho$ and $\int_{-\infty}^{\underline{\rho}} \int_{\underline{x}}^{x^{*}(\mathrm{e}, \underline{\rho})} f(x) g_{\mu, \sigma}(\rho) d x d \rho+\int_{\underline{\rho}}^{\infty} \int_{\underline{x}}^{x^{*}(\mathrm{e}, \rho)} f(x) g_{\mu, \sigma}(\rho) d x d \rho$.

${ }^{28}$ They report that trade credit is a third of all firms' total liabilities in most OECD countries.
} 
Finally, parameters $\mu$ and $\sigma$ are used to construct the distribution of risk aversion, $g_{\mu, \sigma}(\rho)$, with mean risk aversion parameter $\mu=1.55$. In order to better understand the effect of risk aversion on endogenous parameters, table 5 shows how loan size, firm size, financial structure, debt burden and default vary as risk aversion increases. The fraction of net-worth an entrepreneur borrows, $(1-\epsilon) A$, is constant when borrowing constraint (3) binds and falls as risk aversion increases because the borrowing constraint becomes slack. More risk averse agents also run smaller firms, $A$, and use less of their own money, $\epsilon$. As a consequence, firms become more leveraged and debt burden $\bar{v}$ rises, which increases the incentive to default. Consumption is roughly constant except for the agents most willing to bear risk, where current consumption (as a fraction of net worth) is lower because they invest more now to consume more in the future.

Table 5 also allows us to compare our results with Chen, Miao, and Wang (2009). Like us, they find that idiosyncratic firm risk jointly affects owner-manager consumption $(c)$, firm capital structure $(\epsilon)$, and default, among other things. Both models find that more risk averse owners default more, but the capital structure results merit discussion. In their model as risk aversion rises, debt rises. Table 5 shows that in our model as risk aversion rises, total debt falls (row one) while the percentage of debt rises $(1-\epsilon$, based on row three). Three main differences account for this. First, in our model firm size $A$ is a choice variable, while in their model firm size is fixed. Second, borrowing may be constrained in our model, but it is not constrained in theirs. Third, they have CARA preferences, which imply that borrowing is independent of net worth. Recall that credit constraint $(1-\epsilon) A \leq b w$ requires business loans to not exceed $b$ of owner net worth. ${ }^{29}$ Row one of table 5 shows that the credit constraint binds for $\rho \in[0.9,2.1]$, with total debt $(1-\epsilon) A$ stable at 21.5. Row two shows that owners' alter firm size dramatically to manage firm risk as owner risk aversion rises. Our model assesses the importance of these effects quantitatively, producing results consistent with the SSBF: substantial variation in firm size, whether measured by assets or employees (see Herranz, Krasa, and Villamil (2009)), and limits on credit access.

\section{Effects of Limited Liability}

Up to this point we focused on incorporated firms only, and estimated the distribution of risk aversion for entrepreneurs running incorporated firms. Doing a similar exercise for unincorporated firms requires a distribution of return on assets for these firms, which is not possible since owners' wages are not reported. In addition, we would need to calibrate another parameter, the fraction

\footnotetext{
${ }^{29}$ Net worth includes firm and business assets, all terms are divided by $w$, the model determines $b$, and the interest rate on loans is determined in equilibrium by $r(\rho)=\bar{v} /(1-\epsilon)$.
} 
of assets an entrepreneur can retain in bankruptcy, which cannot be done directly for two reasons. First, U.S. bankruptcy is a matter of federal law, but each state sets it own exemption parameter. This would expand the complexity of the model significantly. Second and more fundamental than computational concerns, entrepreneurs make different portfolio choices, which are not observable in the data but determine the amount of assets that can be seized in bankruptcy. As a consequence, we conduct a comparative static analysis to determine the main forces that drive a typical entrepreneur to incorporate or remain unincorporated.

To put the importance of this question into perspective, in the SSBF roughly half the firms are incorporated and half are unincorporated. The main benefit of incorporation is limited liability: an owner's personal assets are separated from firm assets and cannot be seized by creditors. ${ }^{30}$ In order to understand why incorporated and unincorporated small firms co-exist, we focus on the effect of limiting personal liability on an entrepreneur's ex-ante payoff. Our main finding is that less risk-averse owners receive uniformly higher payoffs from incorporation while more risk-averse owners may be better off remaining unincorporated for some values of the bankruptcy exemption parameter. This occurs because less risk-averse owners run bigger firms with higher intertemporal value, which tempers their incentive to default. In contrast, the more risk averse are unable to credibly commit ex-ante to refrain from defaulting ex-post, and putting some personal assets at risk by forgoing incorporation mitigates this commitment problem.

In the baseline model, limited liability corresponds to $\gamma=0$, meaning that no personal assets can be confiscated in bankruptcy. We now relax this assumption by considering a legal system in which an unincorporated owner can be forced to pay $1>\gamma>0$ of personal assets $(w-\epsilon A-c)(1+r)$ to investors in bankruptcy, thus an unincorporated owner is personally liable for some firm debt. ${ }^{31}$ Appendix E modifies Problem 1 to account for $\gamma$. In the objective, $(w-\epsilon A-c)(1+r)$ in the default integral is replaced by $(1-\gamma)(w-\epsilon A-c)(1+r)$. The investor receives $\gamma(w-\epsilon A-c)(1+r)$, after deadweight loss $\delta$ is deducted. Default cutoff $x^{*}$ is also affected and is decreasing in $\gamma$. Appendix E shows that Problem 1 is equivalent to a slightly modified version of Problem 3 in which the integrand over default states is $(1-\gamma)(1-\epsilon A-c)(1+r)$ and the investor receives $(1-\delta) \gamma\left(\frac{1}{A}-\epsilon-\frac{c}{A}\right)(1+r)$, which is divided by assets $A$ since the investor's constraint specifies the

\footnotetext{
${ }^{30} \mathrm{~A}$ secondary benefit is taxation (e.g., a firm may lower self-employment taxes by organizing as an S-corporation). Herranz, Krasa, and Villamil (2009) show that recent firm hybrids account for taxes, yet liability status remains equally divided. Disadvantages include small legal costs and information disclosure requirements.

${ }^{31}$ In the U.S., sole proprietors and partners are personally and jointly responsible for business liabilities. In the extreme case of $\gamma=1$ all personal net-worth can be seized if the firm defaults. In practice, $\gamma=1$ does not occur for unincorporated firms because some private assets are exempt from seizure (e.g. some equity in a home, retirement assets, and personal assets). Thus even if a firm is unincorporated, the effective level of $\gamma$ is significantly less than $100 \%$ and varies across individuals (with different portfolios and asset class exemptions).
} 

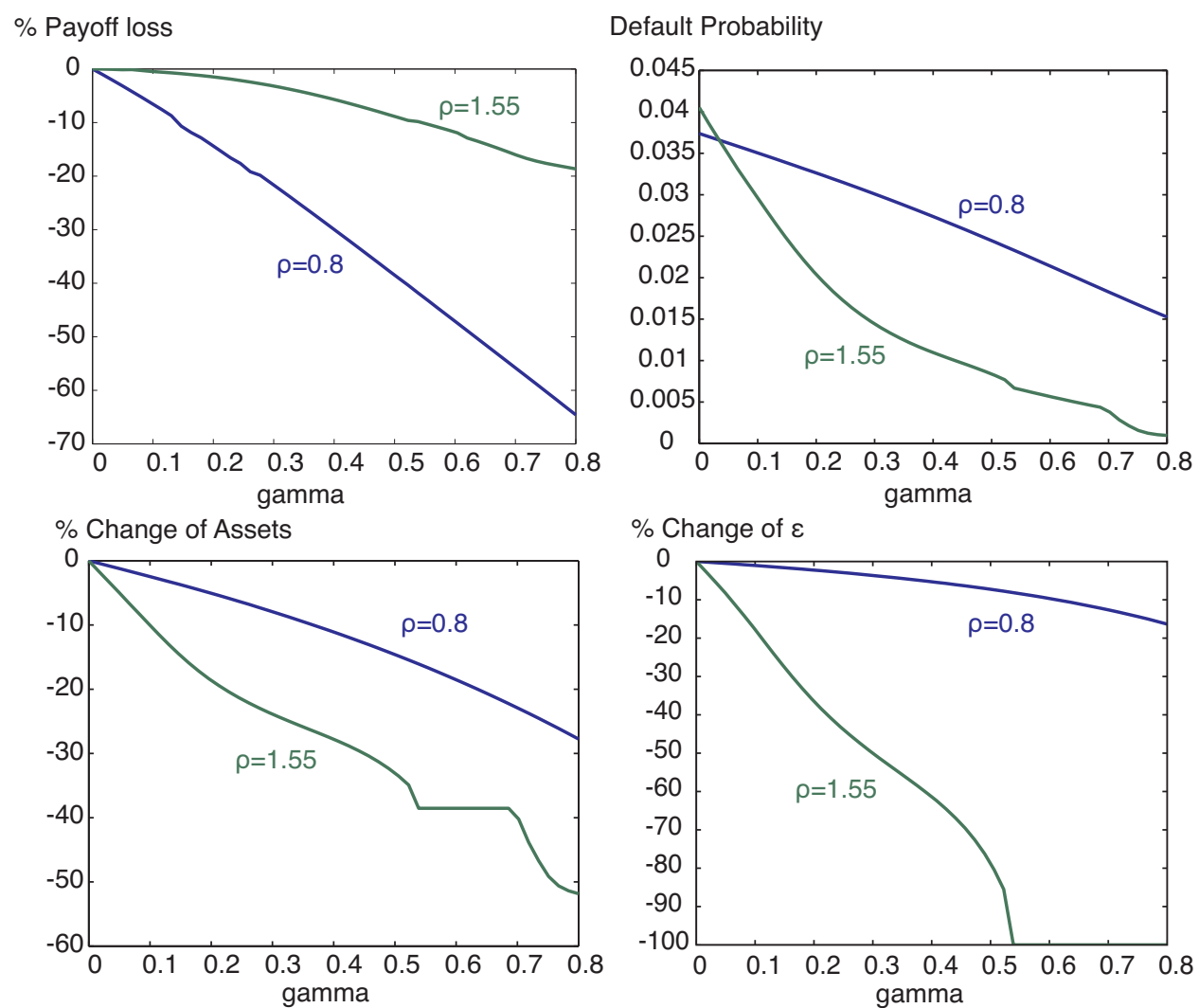

Figure 2: Impact of changes in $\gamma$ on entrepreneurs with lower risk aversion levels

return per unit of assets. We also need a return distribution and constraint parameter. In order to illustrate the costs and benefits of incorporation and facilitate comparison with our previous results, we choose return distribution $f(x)$ constructed for incorporated firms and calibrated parameter $b$ for the borrowing constraint. While differences between incorporated and unincorporated firms may exist, our comparative static results for $\gamma$ remain qualitatively valid.

Figure 2 shows that for agents with below median risk aversion, any positive $\gamma$ decreases owner payoff. $^{32}$ The loss is substantial, especially for those most willing to bear risk. Clearly, such an owner would wish to incorporate to protect personal assets. Raising $\gamma$ is detrimental in this case because while it lowers default (see the top-right panel), this benefit is outweighed by the fact that raising $\gamma$ discourages risk taking, resulting in a substantial decrease in firm size (see the bottomleft panel). The size reduction is bigger for entrepreneurs with $\rho=1.55$, but since less of their net worth is tied up in the firm, their payoff loss is lower. The lower default probability implies

\footnotetext{
${ }^{32}$ We compute the equivalent variation, which for given $\rho$ and $\gamma$ is the $\lambda$ such that $V_{S}^{\gamma}(\lambda w)=V_{S}^{\gamma^{\prime}}(w) ; V_{S}^{\gamma}, V_{S}^{\gamma^{\prime}}(w)$ are value functions in solvency given exemption parameters $\gamma$ and $\gamma^{\prime}$. Proposition 1 implies that $V_{S}^{\gamma}(\lambda w)=\lambda^{1-\rho} V_{S}^{\gamma^{\prime}}(w)$. Further, $V_{S}^{\gamma}(w)=w^{1-\rho} V_{S}^{\gamma}(1)=v_{S}^{\gamma}$ and $V_{S}^{\gamma^{\prime}}(w)=w^{1-\rho} V_{S}^{\gamma^{\prime}}(1)=v_{S}^{\gamma}$. The change is $\lambda=\left(v_{S}^{\gamma} / v_{S}^{\gamma^{\prime}}\right)^{\frac{1}{1-\rho}}$.
} 

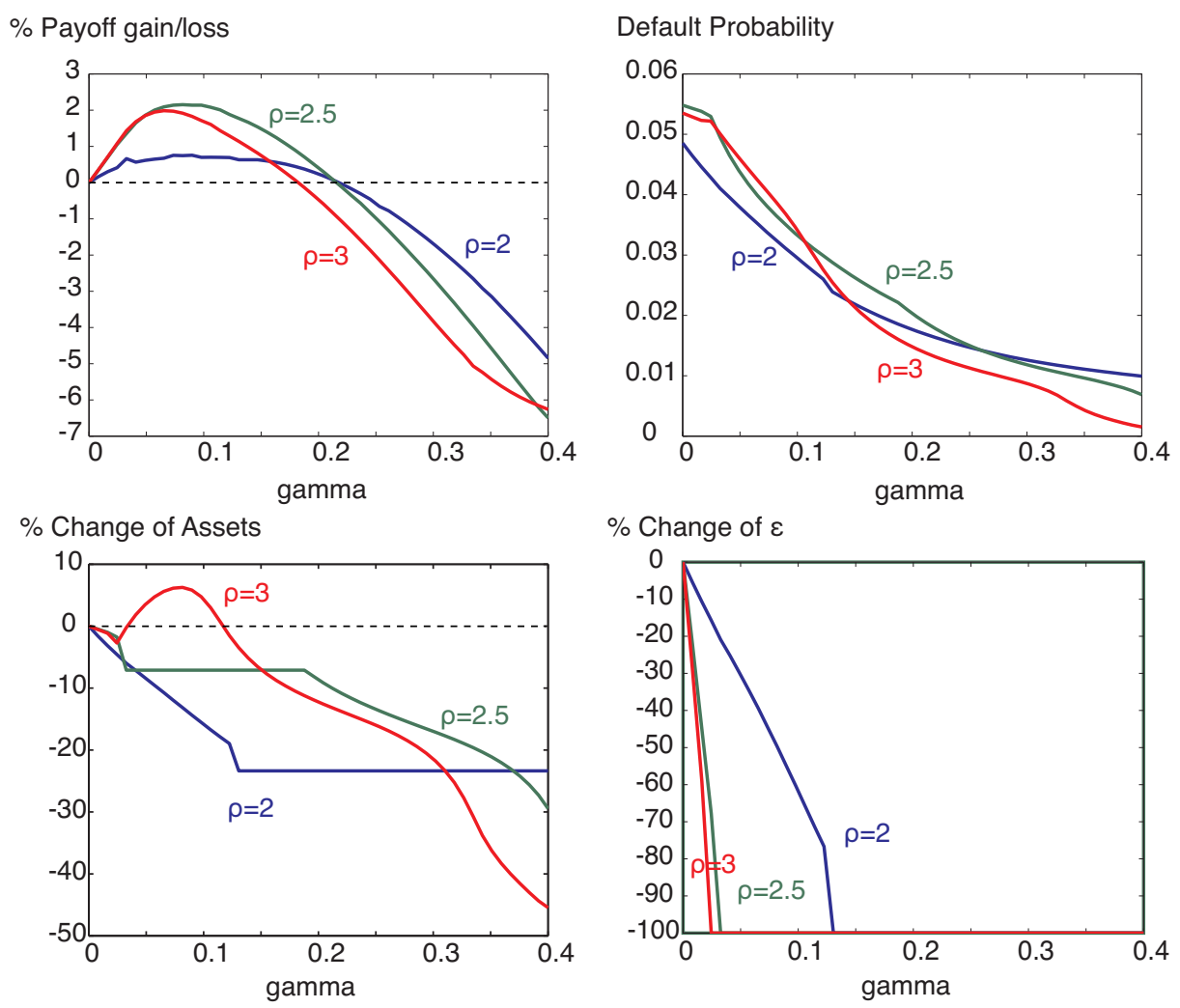

Figure 3: Impact of changes in $\gamma$ on entrepreneurs with higher risk aversion levels

that interest rates and thus borrowing costs decline, hence $\epsilon$ decreases and the firm uses more outside funds. In summary, the net effect of increasing $\gamma$ is a reduction in the insurance provided by bankruptcy, which discourages socially beneficial risk-taking.

In contrast, figure 3 shows that more risk averse agents could increase payoffs by forgoing limited liability for some values of $\gamma$. This occurs because higher $\rho$ agents run smaller firms, hence the loss from exclusion is smaller. This implies that ratio $v_{B} / v_{S}$ is increasing in $\rho$, which in turn implies that $x^{*}$ is larger. ${ }^{33}$ If owners could commit ex-ante to a default cutoff $x_{c}^{*}$ (i.e., if constraint (8) was eliminated), then $x_{c}^{*}<x^{*}$. Thus inability to commit leads to higher default, which is costly. Raising $\gamma$ lowers $x^{*}$, moving the default cutoff closer to the efficient (full commitment) level, $x_{c}^{*}$. Figure 3 illustrates a $\gamma$ for which the benefit outweighs the cost of discouraging risk taking. The figure also shows that increasing $\gamma$ increases firm (asset) size for entrepreneurs with $\rho=3$, but not for those with $\rho=2$ and $\rho=2.5$. Borrowing constraint (10) binds when $\epsilon \rightarrow 0$, and when this occurs $A=b$, i.e., the ex-ante choice of $A$ is constant. This is the flat spot in the lower left figure, where $A$ is

\footnotetext{
${ }^{33}$ Continuation value $v_{S}$ is increasing in $A$, i.e., bigger firms have greater losses from exclusion. Thus $v_{B} / v_{S}<1$, but it converges to 1 as $A \rightarrow 0$.
} 

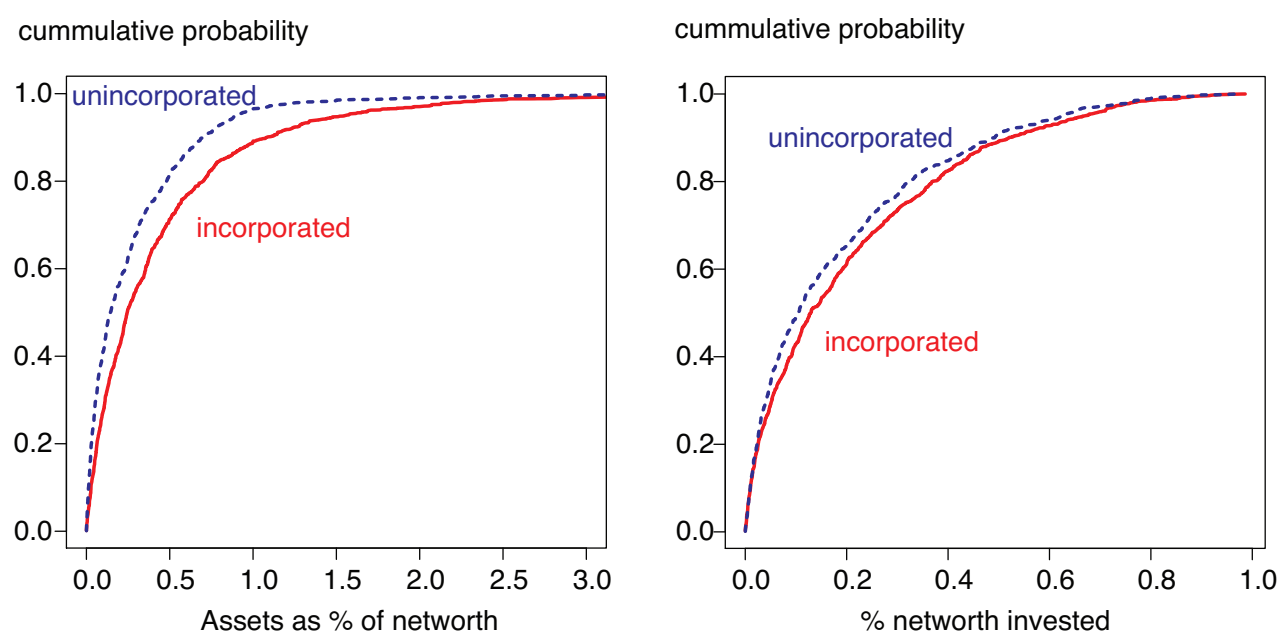

Figure 4: Assets as a fraction of net worth and net worth invested in the firm for 1998

constant over some range (the firm cannot get more debt due to the credit constraint). In contrast, for $\rho=3$ the borrowing constraint is slack for all values of $\gamma$. Raising $\gamma$ lowers borrowing costs and the owner first responds by lowering $\epsilon$, i.e., by using more outside funds. Once $\epsilon=0$ it cannot be reduced further, and lower borrowing costs induce the firm to increase $A$. When $\gamma$ becomes too large, however, the loss of insurance from bankruptcy starts to dominate and $A$ is reduced.

The prediction that more risk-averse owners may remain unincorporated has two observable implications. First, table 5 shows that in the baseline model $(\gamma=0)$ less risk averse owners run larger firms (higher $A$ ), use more personal funds (higher $\epsilon$ ), and risk aversion has little effect on consumption $(c)$. (15) implies that for given $x>0$, more risk averse owners will have a smaller posterior level of $A$. Second, (12) implies that for given $x$, more risk-averse agents will invest less personal wealth in the firm. Figure 4 shows that both implications are true in the SSBF data. ${ }^{34}$

Why do all risk-averse entrepreneurs with a commitment problem not simply incorporate and pledge collateral? For example, the owner of a small unincorporated firm with retirement assets has two options: (i) Withdraw funds from a retirement account and post them as a bond with the lender. This is costly due to early withdrawal penalties and because long-term assets earn higher returns than more liquid investments. (ii) Leave the funds in the retirement account but promise to use them to cover business debts. The agent might renege on the promise or it may not be enforceable by a court. Remaining unincorporated effectively provides collateral when $\gamma$ is known to all parties and enforced by bankruptcy courts at low cost. In practice, remaining unincorporated

\footnotetext{
${ }^{34}$ The distributions in figure 4 report firms with positive equity and owners with positive net worth.
} 
Table 6: Comparative statics for $T$ : Fix $r_{f}=1.2 \%, r=4.5 \%, \beta=0.97, \delta=0.10$

\begin{tabular}{|c|c|c|c|c|c|c|c|c|c|c|c|c|}
\hline$T$ & $\mathbf{6}$ & $\mathbf{7}$ & $\mathbf{8}$ & $\mathbf{9}$ & $\mathbf{1 0}$ & $\mathbf{1 1}$ & $\mathbf{1 2}$ & $\mathbf{1 3}$ & $\mathbf{1 4}$ & $\mathbf{1 5}$ & $\mathbf{1 6}$ & $\mathbf{2 0}$ \\
\hline med $A \%$ & 56.2 & 54.4 & 52.7 & 51.1 & 49.6 & 48.1 & 46.7 & 45.4 & 44.3 & 43.3 & 42.4 & 38.9 \\
default\% & 6.1 & 5.6 & 5.3 & 5.0 & 4.7 & 4.4 & 4.2 & 4.0 & 3.8 & 3.6 & 3.5 & 2.9 \\
cons.\% & 3.7 & 3.7 & 3.7 & 3.7 & 3.7 & 3.6 & 3.6 & 3.6 & 3.6 & 3.6 & 3.6 & 3.6 \\
neg eq\% & 8.4 & 8.8 & 9.3 & 9.7 & 10.0 & 10.6 & 11.1 & 11.9 & 13.4 & 15.1 & 17.0 & 21.0 \\
\hline
\end{tabular}

and pledging collateral may be substitutes, and the desirability of each alternative will depend on opportunity and enforcement costs. Furthermore, the effective amount of personal asset exposure $(\gamma)$ will differ significantly among entrepreneurs. As noted previously, if most of an entrepreneur's net-worth is in home equity and the entrepreneur resides in a state that exempts home equity in bankruptcy, $\gamma$ will be very low, while if the state permits home equity to be seized $\gamma$ will be higher. Thus, the model suggests that more risk averse entrepreneurs are more likely to be unincorporated, but it does not imply a strict cutoff level of $\rho$.

\section{Robustness and Comparative Statics}

Overall, the model can account for key properties of the data. In light of this success, we undertake a series of policy experiments to check robustness and better understand the effect of bankruptcy rules, credit constraints, risk aversion and optimism. We conduct comparative static exercises and use equivalent variation to assess outcomes (utilities of heterogeneous agents cannot be compared). We also perform a counterfactual exercise to show the importance of the return distribution.

\subsection{Bankruptcy Policy: $T, \delta$}

Bankruptcy Exclusion Period T: Consider the effect of changes in $T$ on the owner's payoff, where longer exclusion raises the penalty of bankruptcy. Table 6 fixes $\mu, \sigma, b$, and evaluates the effect of altering the exclusion period from the benchmark $T=11$. As $T$ decreases default increases rapidly. Firm size increases, measured by median asset level $A$. Because $b$ is fixed, the decrease in total investment results in a decrease in equity and an increase in debt, which raises negative equity. One of the main economic arguments in support of recent U.S. bankruptcy reform was that more stringent bankruptcy rules lower interest rates, and therefore help borrowers. Table 13 in Appendix A shows that the loan rate indeed decreases as $T$ increases. However, stricter bankruptcy provides less insurance against bad realizations, and this effect dominates. Table 7 
Table 7: Effects as $T$ Varies: \% change in net-worth compared to benchmark

\begin{tabular}{|c|c|c|c|c|c|c|c|c|c|}
\hline risk aversion $\rho$ & $\mathbf{0 . 9}$ & $\mathbf{1 . 2}$ & $\mathbf{1 . 5}$ & $\mathbf{1 . 8}$ & $\mathbf{2 . 1}$ & $\mathbf{2 . 5}$ & $\mathbf{3 . 0}$ & $\mathbf{3 . 5}$ & $\mathbf{4 . 0}$ \\
\hline$T=6$ & 36.9 & 11.2 & 7.7 & 6.1 & 5.0 & 3.9 & 3.1 & 2.6 & 2.2 \\
$T=8$ & 19.8 & 5.5 & 3.9 & 3.0 & 2.4 & 1.9 & 1.5 & 1.3 & 1.1 \\
$T=10$ & 6.3 & 1.3 & 1.1 & 0.8 & 0.7 & 0.5 & 0.4 & 0.3 & 0.3 \\
$T=11$ & - & - & - & - & - & - & - & - & - \\
$T=12$ & -3.6 & -0.7 & -0.9 & -0.7 & -0.5 & -0.4 & -0.3 & -0.3 & -0.2 \\
$T=14$ & -7.6 & -4.4 & -2.1 & -1.8 & -1.4 & -1.0 & -0.8 & -0.6 & -0.5 \\
$T=16$ & -12.7 & -6.5 & -3.8 & -2.4 & -2.0 & -1.5 & -1.1 & -0.9 & -0.7 \\
\hline
\end{tabular}

shows that lowering the exclusion period increases the owner's payoff, and the model implies that it is optimal to set $T$ as low as possible. Decreasing $T$ is beneficial in the baseline model because it allows a firm to restart and be productive, in accordance with the historical rationale for bankruptcy, though $T=0$ may not be possible or desirable. ${ }^{35}$

The tradeoff between insurance provided by firm bankruptcy and higher interest rates induced by increased default has been analyzed for consumer bankruptcy by Chatterjee, Corbae, Nakajima, and Rios-Rull (2007) and Livshits, MacGee, and Tertilt (2007). In both models consumers trade off insurance against health, divorce or family shocks versus consumption smoothing; the signs of the tradeoffs differ but the welfare effects are modest. ${ }^{36}$ Meh and Terajima (2008) add unincorporated entrepreneurs to the model, and find a larger welfare effect of $1.78 \%$. In contrast, table 7 reports strong effects from reducing the exclusion penalty in our model, particularly for agents with low levels of risk aversion. The main reason for the difference between our model of firm bankruptcy and the consumer bankruptcy models is that reducing the punishment period encourages entrepreneurs to invest more in their firms and operate at a larger scale, which increases output. In this sense, even though we do not find extreme variations in $\rho$, risk interacts with the dynamic decision problem, return distribution and bankruptcy rules to have an important effect on some (heterogeneous) agents, namely those that invest most heavily in their firms.

\footnotetext{
${ }^{35}$ For example, information frictions would make a very low $T$ undesirable. Suppose entrepreneurs could choose between the blueprint return distribution and an alternative with more risk that is socially undesirable. In an institutional environment in which strong ex ante and interim screening mechanisms exist and penalties are credible, a small $T$ can be sufficient to avoid moral hazard or adverse selection. In contrast, a country with poor institutions would require a larger $T$ to deter entrepreneurs from choosing the alternative distribution, thus generating additional inefficiencies.

${ }^{36}$ In our model credit is secured, for example by a house, and "bad luck" is a poor return $x$ rather than the health, job, divorce or family shocks in the consumer models. The first paper finds that when punishment is reduced from 10 to 5 years welfare drops by $0.05 \%$, thus the negative effect from a higher interest rate and tighter borrowing constraint slightly dominates the insurance benefit of a shorter punishment period. The second paper shows that the insurance effect is sometimes weakly dominant, but again the effect is modest.
} 
Table 8: Comparative Statics for $b: r_{f}=1.2 \%, r=4.5 \%, \beta=0.97, \delta=0.10$

\begin{tabular}{|c|c|c|c|c|c|c|c|c|c|}
\hline$b$ & $\mathbf{0 . 1 0}$ & $\mathbf{0 . 1 5}$ & $\mathbf{0 . 2 0}$ & $\mathbf{0 . 2 1}$ & $\mathbf{0 . 2 5}$ & $\mathbf{0 . 3 0}$ & $\mathbf{0 . 3 5}$ & $\mathbf{0 . 4 0}$ & $\mathbf{0 . 5 0}$ \\
\hline median $A$ \% & 46.9 & 47.1 & 47.8 & 48.1 & 49.0 & 50.5 & 51.8 & 52.4 & 52.5 \\
default \% & 3.0 & 3.6 & 4.3 & 4.4 & 4.8 & 5.2 & 5.4 & 5.6 & 5.9 \\
cons. \% & 3.6 & 3.6 & 3.6 & 3.6 & 3.7 & 3.7 & 3.7 & 3.6 & 3.6 \\
neg Eq. \% & 5.7 & 7.7 & 10.0 & 10.6 & 11.7 & 12.9 & 13.6 & 14.2 & 15.0 \\
\hline
\end{tabular}

Bankruptcy Cost $\delta$ : Appendix A analyzes bankruptcy $\operatorname{cost} \delta$ (efficiency in liquidating firm assets) and table 16 shows the effect is minor. However, if $\delta$ is very large and there are large fixed costs to creditors to recover payments in default, agents will try to avoid costly bankruptcy, through debt forgiveness or renegotiation. The static model of Krasa, Sharma, and Villamil (2008) shows that when courts are sufficiently inefficient substantial deadweight losses are possible.

\subsection{Credit Constraints}

Policy can also affect credit constraint parameter $b$. Table 8 shows that increasing $b$ allows firms to borrow more, and hence operate at a larger scale $A$. The higher levels of firm debt, however, increase the fraction of firms who default or have negative equity. Table 9 shows substantial effects from raising $b$ for the least risk averse agents, but not for the more risk averse because for sufficiently high $b$ the credit constraint does not bind. Comparing the effects of $T$ and $b$ shows that an entrepreneur with median $\rho$ benefits more from reducing $T$ than from relaxing the borrowing constraint, in the baseline model. In practice, relaxing the borrowing constraint could be achieved by providing subsidized loans targeted to small business, such as SBA loans.

Table 9: Effect as $b$ Varies: \% change in net-worth compared to benchmark

\begin{tabular}{|c|c|c|c|c|c|c|c|c|c|}
\hline risk aversion $\rho$ & $\mathbf{0 . 9}$ & $\mathbf{1 . 2}$ & $\mathbf{1 . 5}$ & $\mathbf{1 . 8}$ & $\mathbf{2 . 1}$ & $\mathbf{2 . 5}$ & $\mathbf{3 . 0}$ & $\mathbf{3 . 5}$ & $\mathbf{4 . 0}$ \\
\hline$b=0.100$ & -13.1 & -8.5 & -6.2 & -4.9 & -3.7 & -2.2 & -0.9 & -0.2 & -0.1 \\
$b=0.150$ & -6.1 & -4.8 & -3.2 & -2.0 & -1.4 & -0.4 & 0.0 & 0.0 & 0.0 \\
$b=0.200$ & -1.8 & -0.2 & -0.6 & -0.4 & -0.1 & 0.0 & 0.0 & 0.0 & 0.0 \\
$b=0.215$ & - & - & - & - & - & - & - & - & - \\
$b=0.250$ & 8.2 & 1.7 & 1.3 & 0.6 & 0.0 & 0.0 & 0.0 & 0.0 & 0.0 \\
$b=0.300$ & 14.8 & 4.2 & 2.4 & 0.7 & 0.0 & 0.0 & 0.0 & 0.0 & 0.0 \\
$b=0.400$ & 26.6 & 7.2 & 2.7 & 0.7 & 0.0 & 0.0 & 0.0 & 0.0 & 0.0 \\
$b=0.500$ & 35.0 & 7.5 & 2.7 & 0.7 & 0.0 & 0.0 & 0.0 & 0.0 & 0.0 \\
\hline
\end{tabular}




\subsection{Risk Aversion}

Now consider the effect of changes in risk aversion. Clearly policy cannot modify $\mu$, but comparative statics show how owner risk aversion affects the firm. In table 10, as $\mu$ increases, owners run smaller firms. Because $b$ is fixed, these smaller firms have higher debt, which explains why negative equity and default rise with $\mu$. Mazzocco (2006) finds that women are more risk averse than men ( $\rho$ of 5 versus 1.7 ). In our model this parameter change would imply that (i) less women own businesses, (ii) they run smaller firms, ${ }^{37}$ and (iii) they have higher negative equity. The SSBF data indicate that all three model implications are consistent with the data. In 1993 and 1998 women owned $16 \%$ and $24 \%$ of businesses, respectively. In 1998 median assets, normalized by net-worth outside the firm, were $39 \%$ for firms owned by women and $53 \%$ for men (the only year net-worth is reported). Finally, negative equity for women was $19.5 \%$ versus $14.8 \%$ for men, and $26.1 \%$ versus $19.4 \%$ in 1993 and 1998, respectively. Absent the model, the observation that firms run by more risk averse owners have more negative equity might seem counterintuitive.

Table 10: Comparative Statics for $\mu$ : $r_{f}=1.2 \%, r=4.5 \%, \beta=0.97, \delta=0.10$

\begin{tabular}{|c|c|c|c|c|c|c|c|c|}
\hline$\mu$ & $\mathbf{1 . 1 5}$ & $\mathbf{1 . 2 5}$ & $\mathbf{1 . 3 5}$ & $\mathbf{1 . 4 5}$ & $\mathbf{1 . 5 5}$ & $\mathbf{1 . 6 5}$ & $\mathbf{1 . 7 5}$ & $\mathbf{1 . 8 5}$ \\
\hline median $A$ \% & 74.3 & 65.4 & 58.3 & 52.7 & 48.1 & 44.4 & 41.2 & 38.6 \\
default \% & 4.2 & 4.2 & 4.3 & 4.4 & 4.4 & 4.5 & 4.6 & 4.7 \\
cons. \% & 2.8 & 3.0 & 3.2 & 3.5 & 3.6 & 3.8 & 4.0 & 4.1 \\
neg Eq. \% & 8.4 & 8.9 & 9.5 & 10.0 & 10.6 & 11.1 & 11.7 & 12.3 \\
\hline
\end{tabular}

\subsection{Entrepreneur Optimism}

How does optimism by entrepreneurs affect our results? Intuition suggests that less risk averse, less optimistic agents will behave similarly to more risk averse, more optimistic agents. This leads to an identification problem: optimistic agents may be observationally equivalent to less risk averse, non-optimistic agents. We now investigate whether the model has observable implications that are uniquely induced by optimism. Assume that an optimistic entrepreneur believes the firm's return exceeds the true return by some fixed percentage $\bar{o}$. Formally, this implies the entrepreneur assumes that firm returns are $X+\bar{o}$, which yields cdf $H(x-\bar{o})$ in the objective of problem 3 . Assume the lender uses the correct distribution to determine payoff (7) in problem 3.

\footnotetext{
${ }^{37}$ In an interesting study of nascent entrepreneurs, Campbell and DeNardi (2009) table 6 documents that women plan to run smaller firms than men, suggesting an innate difference.
} 

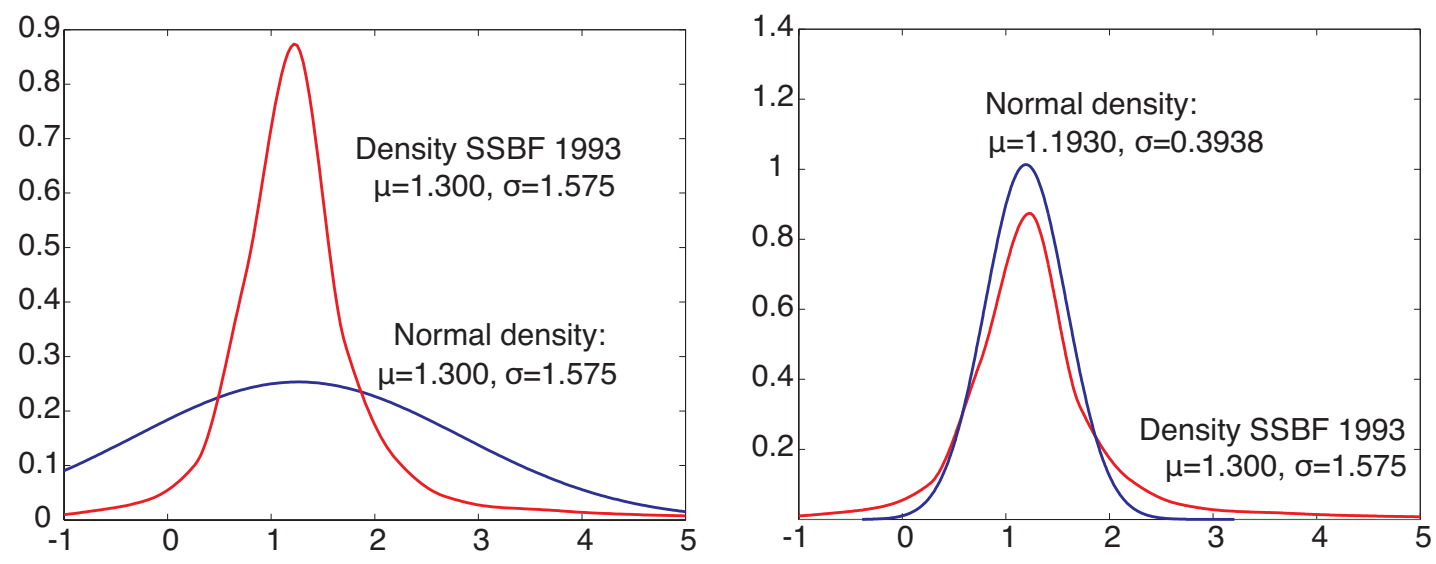

Figure 5: Empirical firm return pdf versus normal pdfs, SSBF 1993

Tables 17 and 18 in Appendix A vary $\bar{o}$ by 5\% and 10\% respectively, and fix all other parameters. ${ }^{38}$ The tables show that slight optimism improves the fit in the baseline model with $T=11$ while keeping $\mu, \sigma$ and the default rate in acceptable ranges. Credit constraint parameter $b$ increases slightly, as does $A$. Negative equity increases to a level consistent with SSBF data because optimistic entrepreneurs run larger firms: they expect higher future returns relative to the baseline and increase total debt $\bar{v}$. Equity is negative if $x<\bar{v}$. When $\bar{v}$ is higher, $x<\bar{v}$ is more likely and this increases the percentage of projects with negative equity. Mild entrepreneur optimism can thus account for the level of negative equity observed in the $1993 \mathrm{SSBF}(15.7 \%)$ and still accommodate the relatively low level of default observed in the data.

\subsection{Counterfactual Exercise: Empirical vs. Normal Returns}

The features of return distribution $f(x)$ are important for understanding entrepreneur behavior. Figure 5 compares the empirical distribution of return on assets for incorporated firms in the 1993 SSBF to two normal distributions with different means and variances. ${ }^{39}$ Clearly, small firms have risky, non-normal returns. The standard deviation is high, with the higher risk somewhat compensated by a higher mean, and the distribution is skewed right with high kurtosis (i.e., a long upper tail), see table 2 . About $12 \%$ of firms lost more than $20 \%$ of assets invested (debt plus equity),

\footnotetext{
${ }^{38}$ Differences in manager ability could be modeled by considering a distribution $H(x, a)$, where $a$ denotes ability. We focus on heterogeneity in risk aversion because it is central to theories of entrepreneurship. Furthermore, firms with very high and low ability will exit the SSBF sample - those with low ability will tend to close down and those with high ability will become too large to be included in the survey. See, for example, Antunes, Cavalcanti, and Villamil (2008), Cagetti and DeNardi (2006) or Meh and Terajima (2008) for models with ability heterogeneity.

${ }^{39}$ We use 1993 data because it is the only SSBF data set with interest expenses, which are required to compute ROA. We consider only incorporated firms with at least $\$ 50,000$ in assets.
} 
7.4\% lost more than $40 \%$, and $3.8 \%$ lost more than $100 \%$. However, positive returns are even more substantial: $20.7 \%$ exceeded $50 \%, 10.4 \%$ exceeded $100 \%$, and $3.8 \%$ exceeded $200 \%$.

We conduct two counterfactual experiments to show that the return distribution is important. The experiments replace the empirical ROA distribution computed from SSBF data, keeping all other benchmark settings the same, with two different normal distributions. In figure 5 the right panel shows the "best fit" normal distribution that minimizes the maximum distance between the normal and empirical cdfs and the left panel shows the normal distribution with the same mean and variance as the empirical distribution.

Best Fit Normal Distribution. Let $g_{\mu, \sigma}$ be the density of a normal distribution with mean $\mu$ and standard deviation $\sigma$ and $f$ be the density of the SSBF distribution. Solve $\min _{\mu, \sigma} \sup _{x}\left|g_{\mu, \sigma}(x)-f(x)\right|$ to find a normal distribution that best approximates the empirical density function. The resulting values are $\mu=1.193$ and $\sigma=0.394$, shown in the right panel of figure 5. In order to fit the "middle" this normal distribution has less mass in the tails and, as a consequence, is less risky. Thus, when re-calibrating the model, median risk aversion increases from 1.55 to 2.33 but at the same time, for given $\rho$, the lower project risk in this normal distribution encourages entrepreneurs to run larger firms. Default is lower, again because this normal distribution has a thinner lower tail. Finally, the thinner upper tail implies that less firms will be "lucky" and have a very good realization. In order to match the distribution of net-worth invested, firms must be more leveraged: Given two solvent firms with the same realization, a more leveraged firm earns a higher return because the owner receives a higher residual after making the fixed debt payment. ${ }^{40}$ The somewhat higher level of debt also implies that more low realizations will result in negative equity, and the predicted percentage of firms with negative equity increases from $10.6 \%$ to $13.7 \%$.

Table 11: Counterfactual Experiment: Normal Distributions

\begin{tabular}{|c|c|c|c|c|}
\hline Parameter & Data & $\begin{array}{c}\text { Empirical } f(x) \\
\text { SSBF } 1993\end{array}$ & $\begin{array}{c}\text { Best Fit Normal } g(x) \\
\mu=1.193, \sigma=0.3938\end{array}$ & $\begin{array}{c}\mu, \sigma \text { Normal } g(x) \\
\mu=1.300, \sigma=1.193\end{array}$ \\
\hline$\mu$ & $1-3$ & 1.55 & 2.33 & $4.4 * 10^{8}$ \\
$\sigma$ & NA & .83 & 1.11 & $7.9 * 10^{8}$ \\
b\% & NA & 21.5 & 30.0 & 23.4 \\
fit & NA & 0.042 & 0.040 & .045 \\
median A\% & {$[43.1,51.9]$} & 48.1 & 54.7 & 38.6 \\
default \% & 3.5 & 4.4 & 1.5 & 61.0 \\
cons. \% & $3-5$ & 3.6 & 4.9 & 3.1 \\
neg. Eq \% & 15.7 & 10.6 & 13.7 & 64.4 \\
\hline
\end{tabular}

\footnotetext{
${ }^{40}$ This also explains the higher value of $b$.
} 
Normal Distribution with SSBF $\mu, \sigma$. The left panel of figure 5 compares the SSBF pdf with a normal distribution with the same mean and standard deviation. Table 11 shows the results for this distribution are significantly at odds with the data, highlighting the importance of the return distribution. First, the fat tails lead to $\mu$ and $\sigma$ with all point mass at $\rho$ and $\bar{\rho}$, where $\bar{\rho}$ is the highest risk aversion for which we compute a solution. Generally, we can choose $\bar{\rho}$ sufficiently high that the mass above $\bar{\rho}$ is negligible; this cannot be done for this normal distribution with fat tails and $\bar{\rho}$ affects the results. ${ }^{41}$ Second, the model predictions in the last column of table 11 are implausible.

\section{Concluding Remarks}

This paper assesses the quantitative effects of changes in legal rules and credit constraints on firms when agents have modest differences in their willingness to bear risk. Corporate bankruptcy insures owners against extreme personal loss, but preserves the possibility of very high future firm returns. The empirical return distribution for small U.S. firms has most mass centered around the middle (see figure 5), which is attractive to individuals with standard degrees of risk aversion, and a long upper tail. Entrepreneurs trade off the value of absorbing a current loss against the option value of maintaining the firm. We find that modest differences in risk aversion interact with policies to generate significant effects on owners' payoffs and firm scale. The model also links firm legal status with owner risk aversion. Less risk-averse owners incorporate to protect personal assets because higher firm option value leads to lower default rates, while if more risk-averse owners run firms they tend to remain unincorporated. This seemingly paradoxical behavior occurs because placing some personal assets at risk of seizure allows more risk-averse owners to solve their "excess default" problem by effectively posting a bond a postiori. Of course, if the legal system is too costly, slow, corrupt, or not credible, bankruptcy will not improve outcomes.

There is a large literature which shows that default is beneficial in risky lending relationships because it introduces a contingency into (non-contingent) debt contracts. Thus, the relatively low default rates observed empirically may be puzzling. We show that although bankruptcy allows riskaverse agents to protect themselves against extremely bad outcomes, even when current realizations are poor owners may use personal assets to "bail out" their firms to avoid bankruptcy. In our model this occurs for three reasons. First, the firm has future option value. Second, a firm uses many strategies to manage risk - including altering its size, capital structure (e.g., injecting equity from personal net-worth), and sometimes choosing to default. Third, the firm's default decision and the bankruptcy rule permit the firm to effectively alter the return distribution, which has the interesting

\footnotetext{
${ }^{41}$ Upper bound $\bar{\rho}$ is needed for computation; it is impossible to compute solutions for a fine grid $[\underline{\rho}, \infty]$.
} 
empirical shape described previously. ${ }^{42}$

A number of extensions to our model are possible. For example, important work by Paulson and Townsend (2006) distinguishes limited liability from moral hazard. In our model the lender can infer agents' risk aversion (e.g., from their loan request), thus adverse selection and moral hazard do not occur. If the coefficient of risk aversion were private information, two types of mis-reports might occur: more risk averse agents could pretend to be less risk averse and vice versa. Our agents would never have an incentive to pretend they are less risk averse because they would pay a higher interest rate in exchange for a larger line of credit, which they do not need (see table 13). They also would not have an incentive to pretend they are more risk averse because they would get a slightly lower interest rate but a significantly smaller loan - table 5 shows that loan size $(1-\epsilon) A$ goes down as $\rho$ rises and table 13 shows that interest rate $\bar{v} /(1-\epsilon)$ does not change significantly. Paulson and Townsend (2006) show that an information friction and a choice between entrepreneurship and wage work creates an important role for moral hazard. In future work we plan to extend our model to quantify the effects of Paulson and Townsend's insight in our framework.

Finally, our model uses a composite lender to aggregate the many sources from which firms obtain loans - banks, trade credit associations, leasing companies, and credit cards. In future work, it would be useful to model the problems of these different lenders. For example, it would be instructive to consider the problem of a bank that must attract deposits and make loans, subject to default risk and regulation. Similarly, trade credit and leasing are important when lenders face information and enforcement problems, as is the case for small firms (e.g., see Eisfeldt and Rampini (2008)). Also, general equilibrium effects are important in credit markets. Increased loan demand will raise the cost of external finance, which will offset some of the gains. Finally, we focus on idiosyncratic firm risk, which is particularly interesting in this setting, because firms are not tradable, and hence the owner cannot diversify this risk. Nonetheless, aggregate risk and correlated shocks would be interesting extensions to further explore macroeconomic implications of the model.

\footnotetext{
${ }^{42}$ Lowering the default rate to zero is not the desideratum. For example, the default rate is zero when no lending occurs, but this is not a desirable outcome.
} 


\section{Appendix A: Robustness}

Table 12 shows that the model is roughly stable when $T$ changes. As $T$ increases, $\mu$ remains between 1.5 and 1.6 and $\sigma$ between 0.74 and 0.9. Liquidity constraint $b$ decreases somewhat because the penalty increases with $T$; entrepreneurs become more cautious and run smaller firms (lower $A$ ) and to achieve the best model fit, the optimization procedure lowers $b$ to ensure they use enough personal funds. Default decreases with $T$ because it is more costly to the entrepreneur. Consumption and negative equity are stable. Table 13 shows that the loan rate decreases as $T$ increases given $\rho$.

Table 12 Benchmark Exogenous Variables: $r_{f}=1.2 \%, r=4.5 \%, \beta=0.97, \delta=0.10$

\begin{tabular}{|c|c|c|c|c|c|c|c|c|}
\hline $\mathbf{T}$ & $\mathbf{1 0}$ & $\mathbf{1 1}$ & $\mathbf{1 2}$ & $\mathbf{1 3}$ & $\mathbf{1 4}$ & $\mathbf{1 5}$ & $\mathbf{1 6}$ & $\mathbf{2 0}$ \\
\hline$\mu$ & 1.62 & 1.55 & 1.49 & 1.51 & 1.52 & 1.52 & 1.51 & 1.50 \\
$\sigma$ & 0.90 & 0.83 & 0.75 & 0.74 & 0.76 & 0.76 & 0.76 & 0.78 \\
$b \%$ & 20.6 & 21.5 & 22.0 & 19.8 & 18.4 & 17.7 & 17.3 & 15.4 \\
fit & 0.046 & 0.042 & 0.037 & 0.034 & 0.034 & 0.034 & 0.035 & 0.036 \\
median $A \%$ & 46.9 & 48.1 & 49.2 & 47.0 & 45.3 & 44.3 & 43.8 & 41.3 \\
default \% & 4.7 & 4.4 & 4.2 & 3.8 & 3.5 & 3.3 & 3.1 & 2.5 \\
cons. \% & 3.7 & 3.6 & 3.6 & 3.6 & 3.6 & 3.6 & 3.6 & 3.5 \\
neg Eq. \% & 10.2 & 10.6 & 10.8 & 10.5 & 10.8 & 11.1 & 11.6 & 11.1 \\
\hline
\end{tabular}

Table 13 Loan Interest Rate $r_{L}$ as $T$ Varies

\begin{tabular}{|c|c|c|c|c|c|c|c|c|c|}
\hline risk aversion $\rho$ & $\mathbf{0 . 9}$ & $\mathbf{1 . 2}$ & $\mathbf{1 . 5}$ & $\mathbf{1 . 8}$ & $\mathbf{2 . 1}$ & $\mathbf{2 . 5}$ & $\mathbf{3 . 0}$ & $\mathbf{3 . 5}$ & $\mathbf{4 . 0}$ \\
\hline$T=0$ & 19.6 & 17.7 & 17.4 & 18.1 & 19.4 & 21.6 & 24.4 & 27.2 & 29.9 \\
$T=6$ & 18.0 & 15.3 & 14.2 & 14.0 & 14.3 & 14.4 & 14.3 & 14.1 & 14.1 \\
$T=8$ & 17.3 & 14.5 & 13.3 & 13.0 & 13.3 & 13.3 & 13.2 & 13.1 & 13.0 \\
$T=10$ & 16.6 & 13.7 & 12.4 & 12.1 & 12.3 & 12.4 & 12.2 & 12.0 & 11.9 \\
$T=11$ & 16.3 & 13.3 & 12.0 & 11.6 & 11.9 & 11.9 & 11.6 & 11.5 & 11.4 \\
$T=12$ & 16.0 & 12.9 & 11.7 & 11.2 & 11.4 & 11.4 & 11.2 & 11.0 & 10.9 \\
$T=14$ & 15.3 & 12.3 & 10.9 & 10.5 & 10.6 & 10.5 & 10.3 & 10.2 & 10.1 \\
$T=16$ & 14.7 & 11.8 & 10.4 & 9.8 & 9.8 & 9.8 & 9.6 & 9.5 & 9.4 \\
$T=20$ & 13.6 & 10.7 & 9.3 & 8.7 & 8.5 & 8.8 & 8.6 & 8.5 & 8.4 \\
\hline
\end{tabular}

Table 14, 15 and 16 show the results are unaffected by substantial changes in bankruptcy cost $\delta$. Compared to the $\delta=0.1$ benchmark in table 12 , table 14 triples $\delta$ and re-estimates the model: $\mu, \sigma, b$ are virtually unaffected, thus the model is robust and detailed cost measurement is not essential in this range. Table 15 reports comparative static results in which $\delta$ varies between 0 and $100 \%$, fixing $b, \mu, \sigma$ at the benchmark values (i.e., the model is not re-estimated). Again, $\delta$ has almost no impact on endogenous variables - in contrast to the comparative statics with respect to $T$. Table 16 shows that $\delta$ has a minor effect (at the median level of risk aversion the gains/losses are less than $0.1 \%$ ) because (a) bankruptcy occurs with only a small probability, and (b) assets $A x$ in bankruptcy states tend to be small so deadweight loss $\delta A x$ is small. Clearly, the expected costs, i.e., the product of (a) and (b) is second order. 
Table 14 Higher Cost $\delta: r_{f}=1.2 \%, r=4.5 \%, \beta=0.97, \delta=0.30$

\begin{tabular}{|c|c|c|c|c|c|c|c|c|}
\hline $\mathbf{T}$ & $\mathbf{1 0}$ & $\mathbf{1 1}$ & $\mathbf{1 2}$ & $\mathbf{1 3}$ & $\mathbf{1 4}$ & $\mathbf{1 5}$ & $\mathbf{1 6}$ & $\mathbf{2 0}$ \\
\hline$\mu$ & 1.79 & 1.67 & 1.55 & 1.50 & 1.52 & 1.52 & 1.51 & 1.50 \\
$\sigma$ & 1.08 & 0.95 & 0.81 & 0.74 & 0.76 & 0.76 & 0.76 & 0.78 \\
$b \%$ & 14.9 & 16.9 & 19.8 & 20.1 & 18.4 & 17.6 & 17.2 & 15.4 \\
fit & 0.052 & 0.046 & 0.040 & 0.035 & 0.034 & 0.034 & 0.035 & 0.036 \\
median $A \%$ & 39.8 & 42.6 & 46.3 & 47.3 & 45.3 & 44.3 & 43.6 & 41.3 \\
default \% & 4.0 & 4.0 & 4.0 & 3.8 & 3.5 & 3.2 & 3.1 & 2.5 \\
cons. \% & 3.8 & 3.7 & 3.7 & 3.6 & 3.6 & 3.6 & 3.6 & 3.5 \\
neg Eq. \% & 8.7 & 9.2 & 10.2 & 10.5 & 10.7 & 11.0 & 11.4 & 11.1 \\
\hline
\end{tabular}

Table 15 Comparative Statics for $\delta$ : Fix $r_{f}=1.2 \%, r=4.5 \%, \beta=0.97, \delta=0.10$

\begin{tabular}{|c|c|c|c|c|c|c|c|c|c|}
\hline$\delta$ & $\mathbf{0 . 0 0}$ & $\mathbf{0 . 1 0}$ & $\mathbf{0 . 2 0}$ & $\mathbf{0 . 3 0}$ & $\mathbf{0 . 4 0}$ & $\mathbf{0 . 5 0}$ & $\mathbf{0 . 6 0}$ & $\mathbf{0 . 8 0}$ & $\mathbf{1 . 0 0}$ \\
\hline fit & 0.042 & 0.042 & 0.046 & 0.050 & 0.054 & 0.057 & 0.060 & 0.063 & 0.065 \\
median $A \%$ & 48.3 & 48.1 & 48.0 & 47.9 & 47.8 & 47.8 & 47.7 & 47.6 & 47.5 \\
default \% & 4.5 & 4.4 & 4.4 & 4.4 & 4.3 & 4.3 & 4.3 & 4.2 & 4.2 \\
cons. \% & 3.6 & 3.6 & 3.6 & 3.6 & 3.6 & 3.6 & 3.6 & 3.6 & 3.6 \\
neg Eq. \% & 10.8 & 10.6 & 10.3 & 10.2 & 10.1 & 10.1 & 10.0 & 9.9 & 9.7 \\
\hline
\end{tabular}

Table 16 Effect as $\delta$ Varies: \% increase or decrease of net-worth compared to benchmark

\begin{tabular}{|c|c|c|c|c|c|c|c|c|c|}
\hline risk aversion $\rho$ & $\mathbf{0 . 9}$ & $\mathbf{1 . 2}$ & $\mathbf{1 . 5}$ & $\mathbf{1 . 8}$ & $\mathbf{2 . 1}$ & $\mathbf{2 . 5}$ & $\mathbf{3 . 0}$ & $\mathbf{3 . 5}$ & $\mathbf{4 . 0}$ \\
\hline$\delta=0.00$ & 0.0 & 0.0 & 0.0 & 0.0 & 0.1 & 0.1 & 0.1 & 0.0 & 0.0 \\
$\delta=0.10$ & - & - & - & - & - & - & - & - & - \\
$\delta=0.20$ & 0.0 & 0.0 & 0.0 & 0.0 & -0.1 & -0.1 & 0.0 & 0.0 & 0.0 \\
$\delta=0.40$ & 0.0 & 0.0 & 0.0 & 0.0 & -0.2 & -0.2 & -0.1 & -0.1 & -0.1 \\
$\delta=0.60$ & 0.0 & 0.0 & 0.0 & -0.1 & -0.4 & -0.3 & -0.2 & -0.1 & -0.1 \\
$\delta=0.80$ & 0.0 & 0.0 & 0.0 & -0.2 & -0.5 & -0.3 & -0.2 & -0.2 & -0.1 \\
$\delta=1.00$ & 0.0 & 0.0 & 0.0 & -0.2 & -0.5 & -0.4 & -0.3 & -0.2 & -0.1 \\
\hline
\end{tabular}


The remaining tables show the effects of slight optimism.

Table 17 5\% Optimism: $r_{f}=1.2 \%, r=4.5 \%, \beta=0.97, \delta=0.10$, optimism $=5 \%$

\begin{tabular}{|c|c|c|c|c|c|c|c|c|}
\hline T & $\mathbf{1 0}$ & $\mathbf{1 1}$ & $\mathbf{1 2}$ & $\mathbf{1 3}$ & $\mathbf{1 4}$ & $\mathbf{1 5}$ & $\mathbf{1 6}$ & $\mathbf{2 0}$ \\
\hline$\mu$ & 1.69 & 1.65 & 1.61 & 1.58 & 1.55 & 1.52 & 1.50 & 1.48 \\
$\sigma$ & 0.75 & 0.71 & 0.68 & 0.66 & 0.64 & 0.63 & 0.62 & 0.62 \\
$b \%$ & 26.4 & 26.2 & 26.3 & 26.7 & 27.0 & 27.3 & 27.2 & 24.4 \\
fit & 0.032 & 0.030 & 0.029 & 0.028 & 0.028 & 0.028 & 0.028 & 0.029 \\
median $A \%$ & 55.1 & 54.9 & 54.8 & 54.7 & 54.7 & 54.7 & 54.5 & 51.5 \\
default \% & 4.7 & 4.4 & 4.1 & 3.9 & 3.7 & 3.6 & 3.4 & 2.7 \\
cons. \% & 4.4 & 4.4 & 4.3 & 4.3 & 4.2 & 4.2 & 4.1 & 4.0 \\
neg Eq. \% & 12.6 & 13.4 & 14.5 & 15.9 & 17.1 & 17.7 & 17.8 & 16.2 \\
\hline
\end{tabular}

Table 18 10\% Optimism: $r_{f}=1.2 \%, r=4.5 \%, \beta=0.97, \delta=0.10$, optimism $=10 \%$

\begin{tabular}{|c|c|c|c|c|c|c|c|c|}
\hline $\mathbf{T}$ & $\mathbf{1 0}$ & $\mathbf{1 1}$ & $\mathbf{1 2}$ & $\mathbf{1 3}$ & $\mathbf{1 4}$ & $\mathbf{1 5}$ & $\mathbf{1 6}$ & $\mathbf{2 0}$ \\
\hline$\mu$ & 1.92 & 1.89 & 1.83 & 1.79 & 1.76 & 1.73 & 1.70 & 1.61 \\
$\sigma$ & 0.83 & 0.81 & 0.77 & 0.74 & 0.72 & 0.70 & 0.69 & 0.63 \\
$b \%$ & 26.6 & 26.2 & 27.0 & 27.2 & 27.3 & 27.3 & 27.3 & 27.4 \\
fit & 0.030 & 0.030 & 0.029 & 0.029 & 0.029 & 0.029 & 0.029 & 0.028 \\
median $A \%$ & 54.9 & 54.1 & 54.8 & 54.8 & 54.8 & 54.8 & 54.8 & 54.7 \\
default \% & 4.4 & 4.0 & 3.8 & 3.6 & 3.4 & 3.3 & 3.1 & 2.7 \\
cons. \% & 5.2 & 5.1 & 5.1 & 5.0 & 5.0 & 4.9 & 4.9 & 4.7 \\
neg Eq. \% & 15.8 & 16.7 & 17.5 & 17.8 & 17.8 & 17.8 & 17.7 & 17.6 \\
\hline
\end{tabular}




\section{Appendix B: Proofs}

Proof of Proposition 1. First, substitute $V_{S}(w)=w^{1-\rho} v_{S}$ and $V_{B}(w)=w^{1-\rho} v_{B}$ into the right-hand side of the objective of problem 1 and in constraint 2. Thus, we get

$$
\begin{aligned}
V_{S}(w)=\max _{c, A, \epsilon, \bar{v}} u(c) & +\beta\left[\int_{\mathfrak{B}}((1+r)(w-\epsilon A-c))^{1-\rho} v_{B} d F(x)\right. \\
& \left.+\int_{\mathfrak{B}^{c}}(A(x-\bar{v})+(1+r)(w-\epsilon A-c))^{1-\rho} v_{S} d F(x)\right]
\end{aligned}
$$

Subject to:

$$
\begin{gathered}
\int_{\mathfrak{B}}(1-\delta) x d F(x)+\int_{\mathfrak{B}^{c}} \bar{v} d F(x) \geq(1-\epsilon)\left(1+r_{f}\right) \\
x \in \mathfrak{B} \Longleftrightarrow v_{B}((1+r)(w-\epsilon A-c))^{1-\rho}>v_{S}(A(x-\bar{v})+(1+r)(w-\epsilon A-c))^{1-\rho} \\
(1-\epsilon) A \leq b w \\
c, A \geq 0,0 \leq \epsilon \leq 1 .
\end{gathered}
$$

Let $\lambda>0$ and let current wealth be $w$. We must prove that $V_{S}(\lambda w)=\lambda^{1-\rho} w$.

Suppose that the entrepreneur's wealth is $\lambda w$ and consumption is changed to $\lambda c$, the firm's assets to $\lambda A$, while $\epsilon$ remains unchanged. Then

$$
\begin{aligned}
& \lambda^{1-\rho} v_{B}((1+r)(w-\epsilon A-c))^{1-\rho}=v_{B}((1+r)(\lambda w-\epsilon \lambda A-\lambda c))^{1-\rho}, \text { and } \\
& \lambda^{1-\rho} v_{S}(A(x-\bar{v})+(1+r)(w-\epsilon A-c))^{1-\rho}=v_{S}(\lambda A(x-\bar{v})+(1+r)(\lambda w-\epsilon \lambda A-\lambda c))^{1-\rho} .
\end{aligned}
$$

This and (19) imply that bankruptcy set $\mathfrak{B}$ remains unchanged. Thus, (18), (20) and (21) are satisfied. Next, note that the right-hand side of the objective changes by the factor $\lambda^{1-\rho}$. Because $V_{S}(\lambda w)$ is the maximum utility of the entrepreneur given wealth $\lambda w$, it follows that

$$
V_{S}(\lambda w) \geq \lambda^{1-\rho} V_{S}(w),
$$

for all $\lambda>0$. Thus,

$$
V_{S}(w)=V_{S}\left(\frac{1}{\lambda} \lambda w\right) \geq \frac{1}{\lambda^{1-\rho}} V_{S}(\lambda w),
$$

which implies that (22) holds with equality. Substituting $w=1$ and $\lambda=w$ in (22) immediately implies that $V_{S}(w)=w^{1-\rho} v_{S}$. The proof that $V_{B}(w)=w^{1-\rho} v_{B}$ is similar. 
Lemma 1 Constraint 1 of Problem 1 binds.

Proof of Lemma 1. Immediate: Suppose by way of contradiction that constraint (1) is slack. Then $\bar{v}$ can be lowered thereby increasing $w_{s}^{\prime}(x)$, which increases the objective of problem $1{ }^{43}$

Lemma 2 Suppose that $\mathfrak{B}$ is non-empty. Let

$$
x^{*}=\bar{v}-\left[1-\left(\frac{v_{B}}{v_{S}}\right)^{\frac{1}{1-\rho}}\right] \frac{(1+r)(1-\epsilon A-c)}{A}
$$

Then $\mathfrak{B}=\left\{x \mid \underline{x} \leq x<x^{*}\right\}$. Conversely, if $x^{*}>\underline{x}$, then bankruptcy set $\mathfrak{B}$ is non-empty. ${ }^{44}$

Proof of Lemma 2. If the entrepreneur chooses to default, the entrepreneur's utility is

$$
u^{B}(x)=[\eta A x+(1+r)(1-\epsilon A-c)]^{1-\rho} v_{B} .
$$

Otherwise, if the entrepreneur does not default, then the utility is

$$
u^{S}(x)=[A(x-\bar{v})+(1+r)(1-\epsilon A-c)]^{1-\rho} v_{S} .
$$

Note that $x \in \mathfrak{B}$ if $u^{B}(x)>u^{S}(x)$ and $x \notin \mathfrak{B}$ if $u^{S}(x) \geq u^{B}(x)$.

Suppose that $u^{S}(x) \geq u^{B}(x)$. We show that $u^{S}\left(x^{\prime}\right)>u^{B}\left(x^{\prime}\right)$ for all $x^{\prime}>x$. Note that

$$
\frac{d\left(u^{S}(x)-u^{B}(x)\right)}{d x}=\frac{(1-\rho)(1-\eta) A v_{S}}{[\eta A x+(1+r)(1-\epsilon A-c)]^{\rho} v_{B}}>0
$$

Thus, $u^{S}(x)-u^{B}(x) \geq 0$ implies that $u^{S}\left(x^{\prime}\right)>u^{B}\left(x^{\prime}\right)$ for all $x^{\prime}>x$. Similarly, $u^{B}(x)>u^{S}(x)$ implies $u^{B}\left(x^{\prime}\right)>u^{S}\left(x^{\prime}\right)$ for all $x^{\prime}<x$. Let $x^{*}$ solve $u^{B}\left(x^{*}\right)=u^{S}\left(x^{*}\right)$. Then the bankruptcy set is given by $\mathfrak{B}=\left\{x \mid \underline{x} \leq x<x^{*}\right\}$. (24) and (25) imply

$$
\left[\eta A x^{*}+(1+r)(1-\epsilon A-c)\right]\left(\frac{v_{B}}{1-\rho}\right)^{1-\rho}=\left[A\left(x^{*}-\bar{v}\right)+(1+r)(1-\epsilon A-c)\right]\left(\frac{v_{S}}{1-\rho}\right)^{1-\rho},
$$

which implies (23).

Now suppose that $x^{*}$ is given by (23) and $x^{*}>\underline{x}$. Then by construction, $u^{S}\left(x^{*}\right)=u^{B}\left(x^{*}\right)$. Further, the monotonicity result established above implies $u^{B}(x)>u^{S}(x)$ for all $x<x^{*}$ and $u^{S}(x) \leq$ $u^{B}(x)$ for all $x \geq x^{*}$. Thus, the bankruptcy set is given by $\mathfrak{B}=\left\{x \mid \underline{x} \leq x<x^{*}\right\}$.

\footnotetext{
${ }^{43}$ The direct effect is to increase the entrepreneur's payoff by decreasing required payments to the lender and the indirect effect is to lower the bankruptcy probability.

${ }^{44}$ At realization $x^{*}$, the entrepreneur is indifferent between default and continuing to operate the firm. Thus, (2) must hold with equality. Solving (2) for $x^{*}$ implies (23).
} 
Proof of Proposition 2. Let $\Gamma\left(v_{S}\right)$ be the maximum entrepreneur utility in Problem 3. We must prove there exists $v_{S}^{*}$ such that $\Gamma\left(v_{S}^{*}\right)=v_{S}^{*}$. First let $\rho>1$. Suppose that $v_{S}=0$. Then $v_{B}<0$. As a consequence, $\Gamma(0)<0$. Now let $\hat{v}_{S}$ be the entrepreneur's expected utility from autarky.

$$
\hat{v}_{S}=\max _{c_{0}, c_{1}, \ldots} \sum_{t=0}^{\infty} \beta^{t} u\left(c_{t}\right)
$$

Subject to:

$$
\sum_{t=0}^{\infty} \frac{c_{t}}{(1+r)^{t}} \leq w \text { and } c_{0}, c_{1}, \ldots \geq 0
$$

Note that if $v_{S}=\hat{v}_{S}$ and we choose $A=0$ in problem 3 then we get the autarky utility $\hat{v}_{S}$. Thus, optimization implies that $\Gamma\left(\hat{v}_{S}\right) \geq \hat{v}_{S}$. Since $\Gamma$ is continuous, the intermediate value theorem implies that there exists a fixed point $v_{S}^{*}$.

For $\rho \leq 1$ we re-normalize $u_{\rho}(x)=\left(x^{1-\rho}-1\right) /(1-\rho)$. Then $\lim _{\rho \rightarrow 1} u_{\rho}(x)=\ln (x)$. Suppose that $v_{S}=0$ and that $u(x)=\ln (x)$. We show that $\Gamma\left(v_{S}\right)<0$.

Let $w_{0}=1-\epsilon A$ be the amount of net-worth not invested in the firm. Because the continuation payoff from non-default is zero we get

$$
\Gamma(0)=\max _{c_{0}, c_{1}, \ldots, c_{T}} \sum_{t=0}^{T} \beta^{t} \ln \left(c_{t}\right)
$$

Subject to:

$$
\sum_{t=0}^{\infty} \frac{c_{t}}{(1+r)^{t}} \leq w_{0}
$$

Furthermore, it is sufficient to prove that the objective of (26) is negative for $w_{0}=1$, because the objective is increasing in $w_{0}$.

The first order conditions immediately reveal that

$$
c_{t}=(1+r)^{t} \beta^{t} c_{0}, \quad c_{0}=\frac{1-\beta}{1-\beta^{T+1}} .
$$

Substituting (27) into the objective of (26) yields

$$
\sum_{t=0}^{T} \beta^{t} \ln \left((1+r)^{t} \beta^{t}\right)+\sum_{t=0}^{T} \beta^{t} \ln \left(c_{0}\right)
$$

If $\beta(1+r) \leq 1$ then (28) is strictly less than 0 . Thus, there exists $\bar{r}(\beta)$ with $(1+\bar{r}(\beta)) \beta>1$ such that $\Gamma(0)<0$ for all $r \leq \bar{r}(\beta)$. By continuity there exists $\underline{\rho}<1$ such that $\Gamma(0)<0$ for $\rho \geq \underline{\rho}$. Finally, $\Gamma\left(\hat{v}_{S}\right) \geq \hat{v}_{S}$ for the autarky level of utility $\hat{v}_{S}$. Thus, continuity of $\Gamma$ implies the existence of a fixed point $v_{S}^{*}$. 


\section{Appendix C: Match Criterion}

We compare criterion (17) to the alternative square distance criterion.

Table 19 Supremum Norm: $r_{f}=1.2 \%, r=4.5 \%, \beta=0.97, \delta=0.10$, optimism $=0.0 \%$

\begin{tabular}{|c|c|c|c|c|c|c|c|c|}
\hline $\mathbf{T}$ & $\mathbf{1 0}$ & $\mathbf{1 1}$ & $\mathbf{1 2}$ & $\mathbf{1 3}$ & $\mathbf{1 4}$ & $\mathbf{1 5}$ & $\mathbf{1 6}$ & $\mathbf{2 0}$ \\
\hline$\mu$ & 1.62 & 1.55 & 1.49 & 1.51 & 1.52 & 1.52 & 1.51 & 1.50 \\
$\sigma$ & 0.90 & 0.83 & 0.75 & 0.74 & 0.76 & 0.76 & 0.76 & 0.78 \\
$b \%$ & 20.6 & 21.5 & 22.0 & 19.8 & 18.4 & 17.7 & 17.3 & 15.4 \\
fit & 0.046 & 0.042 & 0.037 & 0.034 & 0.034 & 0.034 & 0.035 & 0.036 \\
median $A \%$ & 46.9 & 48.1 & 49.2 & 47.0 & 45.3 & 44.3 & 43.8 & 41.3 \\
default \% & 4.7 & 4.4 & 4.2 & 3.8 & 3.5 & 3.3 & 3.1 & 2.5 \\
cons. \% & 3.7 & 3.6 & 3.6 & 3.6 & 3.6 & 3.6 & 3.6 & 3.5 \\
neg Eq. \% & 10.2 & 10.6 & 10.8 & 10.5 & 10.8 & 11.1 & 11.6 & 11.1 \\
\hline
\end{tabular}

Table 20 Square Norm: $r_{f}=1.2 \%, r=4.5 \%, \beta=0.97, \delta=0.10$, optimism $=0.0 \%$

\begin{tabular}{|c|c|c|c|c|c|c|c|c|}
\hline T & $\mathbf{1 0}$ & $\mathbf{1 1}$ & $\mathbf{1 2}$ & $\mathbf{1 3}$ & $\mathbf{1 4}$ & $\mathbf{1 5}$ & $\mathbf{1 6}$ & $\mathbf{2 0}$ \\
\hline$\mu$ & 1.53 & 1.49 & 1.47 & 1.46 & 1.44 & 1.41 & 1.42 & 1.41 \\
$\sigma$ & 0.74 & 0.70 & 0.70 & 0.69 & 0.67 & 0.65 & 0.67 & 0.69 \\
$b \%$ & 21.4 & 21.8 & 20.9 & 20.3 & 20.3 & 20.7 & 19.3 & 17.3 \\
fit & 0.020 & 0.019 & 0.019 & 0.019 & 0.019 & 0.019 & 0.019 & 0.020 \\
median $A \%$ & 50.2 & 50.8 & 49.6 & 49.0 & 48.9 & 49.3 & 47.4 & 44.7 \\
default \% & 4.7 & 4.4 & 4.0 & 3.8 & 3.6 & 3.4 & 3.2 & 2.6 \\
cons. \% & 3.7 & 3.7 & 3.6 & 3.6 & 3.6 & 3.5 & 3.5 & 3.5 \\
neg Eq. \% & 9.8 & 10.2 & 10.1 & 10.3 & 10.9 & 11.7 & 11.8 & 11.5 \\
\hline
\end{tabular}

\section{Appendix D}

\subsection{Construction of the Distribution of Firm Returns}

Herranz, Krasa, and Villamil (2009) use the 1993 SSBF to compute the return on assets (ROA) because it includes interest payments. They exclude unincorporated firms because the SSBF data do not account for the entrepreneur's wage from running the firm. The firm's nominal after-tax ROA is:

$$
x=\frac{\text { Profit after taxes }+ \text { Interest Paid }}{\text { Assets }}+1
$$


Interest paid is added to after tax profit because the ROA must include payments to both debt and equity holders. ${ }^{45}$ The nominal rate is adjusted by $3 \%$ for inflation (BLS CPI 1993). ROA is computed instead of return on equity because many firms had negative equity (about $16 \%$ in the 1993 SSBF and 21\% in 1998). Many of these firms stay in business because owners use personal funds to "bail out the firm." Computing a ROA and modeling owners' allocations of equity and debt accounts for this. ${ }^{46}$

\subsection{Numerical Procedure}

Given model parameters, compute solutions to problem 3 as follows. For fixed $v_{S}$, use the first order conditions to solve for the optimum. (9) is always slack, since $c+\epsilon A=1$ would imply zero future consumption. We need only verify if (10) and (or) (11) bind by checking for positive Lagrange multipliers in the first order conditions. Inserting the solution of the first order conditions into the objective yields $\Gamma\left(v_{S}\right)$. To find a fixed point, compute slope $\Gamma^{\prime}\left(v_{S}\right)$ by the Envelope Theorem or compute the difference of $\Gamma$ between $v_{S}$ and a point $v_{S}^{\prime}$, giving solution $\epsilon, A, c, \bar{v}$. Section 3.2 explains how to go from these point estimates to cdfs. Compute $\rho$ from the first order condition using the fact that $v_{S} \rightarrow \infty$ as $\rho \downarrow \underline{\rho} .^{47}$

\section{Appendix E: Limited Liability}

Suppose that entrepreneur can be forced to pay a percentage $\gamma$ of private assets in the case of default. This yields the following optimization problem for an individual entrepreneur.

Problem $4 V_{S}(w)=\max _{c, A, \epsilon, \bar{v}} u(c)+\beta\left[\int_{\mathfrak{B}} V_{B, 1}((1-\gamma)(1+r)(w-\epsilon A-c)) d F(x)\right.$

$$
\left.+\int_{\mathfrak{B} c} V_{S}(A(x-\bar{v})+(1+r)(w-\epsilon A-c)) d F(x)\right]
$$

\section{Subject to:}

$$
\begin{gathered}
\int_{\mathfrak{B} \cap \mathbb{R}_{-}} x d F(x)+\int_{\mathfrak{B}_{\mathbb{R}_{+}}}(1-\delta) x d F(x) \\
+\int_{\mathfrak{B}} \gamma(1-\delta)\left(\frac{w}{A}-\epsilon-\frac{c}{A}\right) d F(x)+\int_{\mathfrak{B}^{c}} \bar{v} d F(x) \geq(1-\epsilon)\left(1+r_{f}\right) \\
x \in \mathfrak{B} \text { if and only if } V_{B, 1}((1-\gamma)(1+r)(w-\epsilon A-c))>V_{S}(A(x-\bar{v})+(1+r)(w-\epsilon A-c))
\end{gathered}
$$

\footnotetext{
${ }^{45}$ We use after tax returns as this is relevant for an entrepreneur to decide how much net-equity to invest.

${ }^{46}$ Computing ROE is misleading for firms near distress. For firms with low but positive equity, small profit gives a high percentage return. Also, many loans are collateralized; book value of equity understates owner contribution (the "correct" value of equity).

${ }^{47}$ Choose a large value for $v_{S}$, solve for the remaining parameters including $\rho$, which approximates $\underline{\rho}$. In other words, rather than solving the fixed point problem for $v_{S}$, solve it for $\rho$.
} 


$$
\begin{gathered}
(1-\epsilon) A \leq b w \\
c \geq 0, A \geq 0,0 \leq \epsilon \leq 1 .
\end{gathered}
$$

Note that the investor's constraint is normalized by assets. Thus, the payment in bankruptcy states made out of the entrepreneur's personal assets must be divided by $A$.

Again, suppose that the entrepreneur's wealth is $\lambda w$ and consumption is changed to $\lambda c$, the firm's assets to $\lambda A$, while $\epsilon$ remains unchanged. Then as in the proof of Lemma 1 we can show that the constraints of Problem 4 are satisfied and that $V_{S}(\lambda w)=\lambda^{1-\rho} V_{S}(w)$. Similarly, it follows again that $V_{B}(\lambda w)=\lambda^{1-\rho} V_{B}(w)$. Thus, we get an optimization problem that is analogous to Problem 3 .

Problem $5 v_{S}=\max _{c, A, \epsilon, \bar{v}} u(c)+\beta v_{B} \int_{\underline{x}}^{x^{*}}[(1+r)((1-\gamma)(1-\epsilon A-c))]^{1-\rho} d F(x)$

$$
\left.+\beta v_{S} \int_{x^{*}}^{\bar{x}}[A(x-\bar{v})+(1+r)(1-\epsilon A-c)]^{1-\rho} d F(x)\right]
$$

\section{Subject to:}

$$
\begin{gathered}
\left.\left.\left.\int_{\underline{x}}^{x^{*}} \min \{x,(1-\delta) x\} d F(x)+\int_{\underline{x}}^{x^{*}} \gamma(1-\delta)\left(\frac{1}{A}-\epsilon-\frac{c}{A}\right) d F(x)+\int_{x^{*}}^{\bar{x}} \bar{v} d F(x) \geq(1-\epsilon)\left(1+r_{f}\right)(34)\right)\left(\underline{v_{B}}\right)^{\frac{1}{1-\rho}}\right] \frac{(1+r)(1-\epsilon A-c)}{A}, \underline{x}\right\} \\
x^{*}=\max \{\bar{v}-[1-(1-\gamma+\epsilon A \leq 1 \\
(1-\epsilon) A \leq b \\
c \geq 0, A \geq 0,0 \leq \epsilon \leq 1
\end{gathered}
$$

Note that for $\gamma=0$ this problem is equivalent to Problem 3. 


\section{References}

Abbring, J. and J. Campbell (2005). A firm's first year. Tinbergen Institute working paper 5-46.

Antunes, A., T. Cavalcanti, and A. Villamil (2008). The effect of financial repression and enforcement on entrepreneurship and economic development. Journal of Monetary Economics 55, 278-297.

Athreya, K. (2002). Welfare implications of the bankruptcy reform act of 1999. Journal of Monetary Economics 49, 1567-1595.

Boissay, F. and R. Gropp (2007). Trade credit defaults and liquidity provision by firms. Working Paper No. 753, European Central Bank.

Boyd, J. and B. Smith (1994). How good are standard debt contracts? Stochastic versus non stochastic monitoring in a costly state verification environment. Journal of Business 67, $539-561$.

Bris, A., I. Welch, and N. Zhu (2006). The cost of bankruptcy: Chapter 7 liquidation versus chapter 11 reorganization. Journal of Finance 111, 1253-1303.

Cagetti, M. and M. DeNardi (2006). Entrepreneurship, frictions, and wealth. Journal of Political Economy 114, 835-870.

Campbell, J. R. and M. DeNardi (2009). A conversation with 590 nascent entrepreneurs. Annals of Finance 5, 313-340.

Chatterjee, S., D. Corbae, M. Nakajima, and V. Rios-Rull (2007). A quantitative theory of unsecured consumer credit with risk of default. Econometrica 75, 1525-1589.

Chen, H., J. Miao, and N. Wang (2009). Entrepreneurial finance and non-diversifiable risk. NBER Working Paper No. 14848.

Eisfeldt, A. and A. Rampini (2008). Leasing, ability to repossess, and debt capacity. Review of Financial Studies 21, 289-309.

Evans, D. S. and B. Jovanovic (1989). An estimated model of entrepreneurial choice under liquidity constraints. Journal of Political Economy 97, 808-827.

Glennon, D. and P. Nigro (2005). Measuring the default risk of small business loans: A survival analysis approach. Journal of Money Credit and Banking 37, 923-947.

Harrison, G., J. List, and C. Towe (2009). Naturally occurring preferences and exogenous laboratory experiments: A case study of risk aversion. Econometrica 2, 433-458. 
Herranz, N., S. Krasa, and A. Villamil (2009). Small firms in the ssbf. Annals of Finance 5, 341-359.

Hovenkamp, H. (1991). Enterprise and American Law. Cambridge, MA: Harvard University Press.

Kihlstrom, R. and J. Laffont (1979). A general equilibrium entrepreneurial theory of firm formation based on risk aversion. Journal of Political Economy 87, 719-749.

Knight, F. H. (1921). Risk, Uncertainty and Profit. Boston, MA: Hart, Schaffner \& Marx; Houghton Mifflin.

Krasa, S., T. Sharma, and A. Villamil (2008). Bankruptcy and firm finance. Economic Theory 3, 595-609.

Krasa, S. and A. Villamil (2000). Optimal contracts when enforcement is a decision variable. Econometrica 68, 119-134.

Krasa, S. and A. Villamil (2003). Optimal contracts when enforcement is a decision variable: A reply. Econometrica 71, 391-393.

Krusell, P. and A. Smith (1998). Income and wealth heterogeneity in the macroeconomy. Journal of Political Economy 106, 867-896.

Livshits, I., J. MacGee, and M. Tertilt (2007). Consumer bankruptcy: A fresh start. American Economic Review 97, 402-418.

Mann, B. (2003). Republic of Debtors: Bankruptcy in the Age of American Independence. Cambridge, MA: Harvard University Press.

Mazzocco, M. (2006). Individual rather than household euler equations: Identification and estimation of individual preferences using household data. http://www.ccpr.ucla.edu/asp/Mrsch.asp.

Meh, C. and Y. Terajima (2008). Unsecured debt, consumer bankruptcy and entrepreneurship. working paper, Bank of Canada.

Mester, L. (1997). What's the point of credit scoring? Business Review 3, 3-16.

Paulson, A. and R. Townsend (2006). Distinguishing limited liability from moral hazard in a model of entrepreneurship. Journal of Political Economy 114, 100-145.

Prescott, E. C. (2006). The transformation of macro policy and research. Journal of Political Economy 114, 203-236.

Quadrini, V. (2009). Entrepreneurship in macroeconomics. Annals of Finance 5, 295-311. 
Vereshchagina, G. and H. Hopenhayn (2008). Risk taking by entrepreneurs. American Economic Review 86, 562-583. 